NBER WORKING PAPER SERIES

\title{
INTERNATIONAL HEALTH ECONOMICS
}

\author{
Mark Egan \\ Tomas J. Philipson \\ Working Paper 19280 \\ http://www.nber.org/papers/w19280
}

\author{
NATIONAL BUREAU OF ECONOMIC RESEARCH \\ 1050 Massachusetts Avenue \\ Cambridge, MA 02138 \\ August 2013
}

We are thankful to Gary Becker, Anupam Jena, Dana Goldman, Darius Lakdawalla, Jonathan Adams, and Casey Mulligan for comments as well as seminar participants at The University of Chicago, TEDMED, Yale University, Peking University, The Milken Institute Global Conference, University of Southern California, and The Scientific American Super Session at BIO. The views expressed herein are those of the authors and do not necessarily reflect the views of the National Bureau of Economic Research.

NBER working papers are circulated for discussion and comment purposes. They have not been peerreviewed or been subject to the review by the NBER Board of Directors that accompanies official NBER publications.

(C) 2013 by Mark Egan and Tomas J. Philipson. All rights reserved. Short sections of text, not to exceed two paragraphs, may be quoted without explicit permission provided that full credit, including $\odot$ notice, is given to the source. 
International Health Economics

Mark Egan and Tomas J. Philipson

NBER Working Paper No. 19280

August 2013

JEL No. F0,F42,I1,I11,I18

\begin{abstract}
Perhaps because health care is a local service sector, health economists have paid little attention to international linkages between domestic health care economies. However, the growth in domestic health care sectors is often attributed to medical innovations whose returns are earned worldwide. Because world returns drive innovation and innovation is central to spending growth, spending growth in a given country is thereby highly affected by health care economies and policies of other countries. This paper analyzes the unique positive and normative implications of these innovation-induced linkages across countries when governments centrally price health care. Providing world returns to medical innovation under such central pricing involves a public-goods problem; the taxation to fund reimbursements involves a private domestic cost with an international benefit of medical innovation. This has the direct normative implication that medical innovations have inefficiently low world returns. It also has the positive implication that reimbursements in one country depend negatively on those of others; reimbursements are "strategic substitutes" through free riding. Because reimbursements are strategic substitutes, world concentration of health care is a significant issue. A small European country has no access-innovation trade-off in its pricing; it will have low reimbursements because it does not affect world returns and sees the same innovations regardless of its reimbursement policy. The public-goods problem of innovation thereby implies that the United States, despite being the world's largest buyer, will pay the highest reimbursements. This problem also implies that free riding counteracts the standard positive impact of larger world markets on innovation when health care concentration falls. Indeed, currently, health care is highly concentrated; about half of world health care spending occurs in the United States, despite that fact that it makes up only about one-fifth of the world economy. We assess the effect that emerging markets will have on this concentration and thus world returns. We use pharmaceutical reimbursement data from 1996-2010 to provide IV estimates of the degree to which domestic reimbursements are strategic substitutes. We find that these estimates imply that world returns from innovation may actually fall from a growth in "market size" of BRICS countries as a result of increased free riding in non-BRICS countries. The overall analysis has important positive implications for spending patterns across countries as well as normative implications for evaluating domestic or regional health care reforms.
\end{abstract}

\author{
Mark Egan \\ University of Chicago \\ Department of Economics \\ 1126 East 59th Street \\ Chicago, IL 60637 \\ egan@uchicago.edu \\ Tomas J. Philipson \\ Irving B. Harris Graduate School \\ of Public Policy Studies \\ University of Chicago \\ 1155 E. 60th Street \\ Chicago, IL 60637 \\ and NBER \\ t-philipson@uchicago.edu
}




\section{Section 1: Introduction}

Perhaps because health care is primarily a local service industry, health economists have paid relatively little attention to international trade issues. Nevertheless, the health economics research community holds the widespread belief that medical innovation is a central force behind the worldwide growth of spending (Newhouse, 1992). Today, most countries are spending on technologies, or physician- and hospital services connected to those technologies, unavailable just a few years ago. Reimbursements, either direct or indirect, create the incentive to innovate. Payments for pharmaceuticals would be an example of a direct reimbursement, while payments to hospitals or doctors for devices used in patient care would be an example of an indirect reimbursement.

However, it is well understood that research and development (R\&D) in general and medical innovation in particular are driven by world returns rather than returns of a given domestic market. For example, Swedish medical product firms innovate to sell worldwide not just to their own small population. Because world returns drive innovation and are central to health care spending growth, it follows that a given country's spending growth is driven by health care economies and policies of other countries. As such, spending growth in a small European country currently depends on how US policies affect world returns, just as future Medicare spending will depend on how emerging markets will affect those returns. However, health economists have conducted little explicit analysis on how health care policies in one country affect or should affect those of another. This paper analyzes the positive and normative implications of these innovation-induced linkages between domestic health care economies and centrally set reimbursement policies.

We argue that domestic governments' centralized pricing of much of health care has some unique implications for determining world returns and the innovation-induced spending growth those returns imply. In particular, the act of setting reimbursement policies for providers and manufacturers, whether by allowing private pricing or public reimbursements, creates a public-goods problem in generating world returns to medical innovation. Taxation to fund the reimbursements to the health care industry involves a 
private cost with a worldwide benefit through innovation. It follows directly that if medical innovation benefits all countries, a given country under-reimburses providers and manufacturers as a result of its positive external effect on others. Thus, there will be too little medical innovation as it will not be sufficiently rewarded by world returns.

A key positive implication of this public-goods problem is that profit-provision through reimbursements in a given country is negatively correlated with the profit provision of other countries; that is, reimbursements will be "strategic substitutes." A small European country may reimburse less generously because the United States reimburses more generously. More precisely, we argue that the smaller the share of world demand and supply a country makes up, the less that governments will mark up prices above cost to promote innovation. Put differently, a small country has nothing to gain from raising its reimbursements, as it will see the same flow of new innovations regardless of what it does. We therefore predict that European countries will have lower payments and reimbursements than the United States, despite the latter being the larger buyer. This may be reflected in relatively lower European reimbursements for doctor and hospital services that cover innovations such as devices or drugs or for medical products directly through reference pricing or cost-effectiveness threshold policies. ${ }^{2}$

We analyze how changes in both worldwide demand and supply drive world returns when reimbursements are strategic substitutes. We predict that the concentration of aggregate demand and supply across the world has implications for medical innovation. These concentration effects have nonstandard consequences for the future of medical innovation and world spending growth. For example, future growth in world demand from the emerging markets of Brazil, Russia, India, China, and South Africa (or BRICS), despite recent slowdowns, will lower world concentration of aggregate demand and supply by making the United States less dominant. We predict that this will lead to lower US reimbursements when it loses it dominant role in world returns. In general, growth in

\footnotetext{
2 Philipson and Jena (2008) discusses the implicit price controls that reimbursement based on costeffectiveness standards implies.
} 
world markets may have two offsetting effects on innovation: the standard positive effect from an increase in world market size, and the offsetting negative effect due to increased free riding when world concentration in health care falls.

We provide empirical evidence of these effects by analyzing the impact of the growth of BRICS on future world returns and. In doing so, we provide some basic facts on world concentration in health care, including the degree to which the share of the world supply of medical products from BRICS has risen relative to their share of world demand. We then use pharmaceutical reimbursement data from 26 developed countries over the past 15 years to provide instrumental variable (IV) estimates of the degree to which reimbursements are strategic substitutes to demand and supply conditions of other countries.

We use these IV estimates to assess the impact on world returns of a diminishing concentration created by the growth of BRICS. A back-of-the-envelope calculation illustrates that the markup reductions in the United States and other countries do not have to be large to offset predicted growth rates in demand from BRICS. Currently, the BRICS contribute approximately $7 \%$ to world spending in health care. If by current industry estimates, such as that of IMS Health ${ }^{3}$, their spending grew $20 \%$ in the next three years, they would still make up only about $8.28 \%$ of world spending. This implies that a decrease in markups of only $1.5 \%$ in non-BRICS countries would be enough to offset this $20 \%$ growth from BRICS. The small reduction in markups needed to offset the substantial spending growth from the BRICS is due to the substantial concentration in world health care spending. Our estimates of the size of the strategic substitutability in reimbursements suggest that under reasonable conditions, when world concentration of health care supply and demand falls, the growth in BRICS market size may lower medical innovation returns as a result of declines in reimbursements in the United States and other rich countries.

\footnotetext{
${ }^{3}$ This is the suggested growth rate in industry publications, see e.g. IMS Institute's "The Global Use of Medicines Outlook Through 2016"
} 
Our analysis relates to several other strands of work. Becker et al. (2005) documented that medical innovation in rich countries greatly affected health outcomes in poor countries and reduced world inequality. Hult and Philipson (2012) considered the impact of domestic, rather than international, reimbursement policies on innovation incentives. Lakdawalla et al. (2009) simulated the impact of US pharmaceutical pricing policies on both US and European health outcomes. Danzon (1997) discussed how to efficiently raise a given amount of pharmaceutical R\&D across regions through Ramsey pricing. This research differs from our strategic analysis, wherein positive and normative implications stem from inefficiencies in the public-goods provision of world returns. ${ }^{4}$ Our analysis also relates to a large literature comparing domestic health care economies (see, e.g., Gerdtham and Jönsson, 2000), which does not consider the innovation-induced linkages across countries we discuss here.

The overall point of our analysis is to analyze how international linkages affect both positive and normative analyses of domestic health care policies. On a positive level, these linkages seem to be important for explaining differences in European and US reimbursement policies and hence spending differences; on a normative level, they are important for evaluating the effects and desirability of domestic health care reforms aimed at curbing domestic spending growth resulting from world returns.

The paper is structured as follows: Section 2 provides a theoretical examination of the implications of the innovation-induced linkages among domestic reimbursement policies. Section 3 provides our empirical analysis of strategic substitutability and the impact of the BRICS on future world returns. Section 4 concludes and discusses future research, including the limited value of regional- or state-level reimbursement experiments in examining spending growth induced by world returns.

\footnotetext{
${ }^{4}$ In addition their analysis implies the central importance of the price-elasticity of medical product demand in efficiently raising a given amount of R\&D, which is less relevant when reimbursements are centrally set and publicly financed in which case the excess burden of taxation is the dead weight loss of interest.
} 


\section{Section 2: The Public Goods Problem of Providing World Returns to Innovation}

We first lay out the framework considered for the public goods problem of providing world returns for medical innovation. The key issue is that protecting innovator profits through higher public reimbursements involves private cost for a country, but this provision has positive external effects to other countries by promoting innovation.

Therefore, public reimbursements will be under-provided by countries acting in their own interest compared to efficient world returns and reimbursements will be strategic substitutes.

Consider when the amount of R\&D affects the probability of discovery of a medical innovation according to $P(R)$ where $P(\cdot)$ is increasing and concave. If $\Pi=\sum_{k=1}^{K} \pi_{k}$ are the world profits aggregated up over K countries then the R\&D that maximizes expected profits can be written as $R(\Pi)=\operatorname{argmax}_{R} P(R) \Pi-R$. This implies that the induced probability of discovery $P(\Pi)=P(R(\Pi))$ is increasing in world profits $\Pi$.

Each country provides profits $\pi_{k}$ and has its own welfare $w\left(\pi_{k}\right)$ which is decreasing in profit provision given the excess burden of the taxes financing reimbursements. The world expected social welfare across all countries is

$$
\sum_{k=1}^{K} P(\Pi) w\left(\pi_{k}\right)
$$

Within a given country, providing profits is a private bad that enables the public good of world returns to innovation. The socially efficient profit provision of each country therefore satisfies a classic public good condition that the private cost of raising reimbursement is equated to the value to the world of raising innovative returns

$$
\sum_{k=1}^{K} P^{\prime}(\Pi) w\left(\pi_{k}\right)=-P(\Pi) w^{\prime}\left(\pi_{k}\right) \quad k=1,2, \ldots K
$$


This efficient provision of profits differs from the privately optimal (Nash equilibrium) provision which only takes into account how the country's costly profit provision affects its own welfare

$$
P^{\prime}(\Pi) w\left(\pi_{k}\right)=-P(\Pi) w^{\prime}\left(\pi_{k}\right)
$$

Thus, the private innovation benefit to a given country is smaller than the social benefit to all countries so that world returns to medical innovation are under-provided by countries when acting in their own interest. In other words, the Nash equilibrium of profit provision has world returns to innovation below the efficient level ${ }^{5}$.

This public goods problem of providing world returns alters standard arguments about the classic effects of market size on innovation. In particular, the public goods problem may counteract the canonical positive effect that a growth of world markets has on innovative returns. To see this in its simplest form, consider when there are $\mathrm{K}$ homogeneous countries with the same domestic profits $\pi(K)$. An increase in the number of countries may be interpreted as the rise in "profitable" countries for which demand is above variable costs, such e.g. the growth of world demand through the BRICS. The FOC for privately optimal profit provision in this case implies

$$
P^{\prime}(K \pi) w(\pi)=-P(K \pi) w^{\prime}(\pi)
$$

Under regularity conditions ${ }^{6}$ this implies free-riding in the sense that that domestic profits fall with the number of countries that contribute to world profits; $\frac{d \pi}{d K}<0$. World returns are $\Pi=\pi(K) K$ and thus there are two effects of a growth in world market size on world returns

\footnotetext{
${ }^{5}$ More precisely, for any profit level $\pi_{k}$ the marginal cost of profit provision $\left(P(\Pi) w^{\prime}\left(\pi_{k}\right)\right)$ is the same under socially optimal and privately optimal setting; However, for any profit level $\pi_{k}$, the marginal benefit of profit provision is greater under the socially optimal framework than the privately optimal framework $\left(P^{\prime}(\Pi) \sum_{j=1}^{K} w\left(\pi_{j}\right)>P^{\prime}(\Pi) w\left(\pi_{k}\right)\right)$. Consequently, profits are underprovided in the privately optimal setting.

${ }^{6}$ Sufficient but not necessary conditions for $\frac{d \pi}{d K}<0$ are that $P(\Pi)$ is increasing and concave in total profits and $w(\pi)$ is decreasing and concave in domestic profits.
} 


$$
\frac{d \Pi}{d K}=\pi+\pi^{\prime}(K) K
$$

This says that the first standard positive effect of market size on innovative returns is mitigated by the second negative effect induced by increased free-riding when a larger group of countries provides the public good of medical innovation. In the extreme case when US or a single country is the only champion of medical innovative returns, $K=1$, world returns are efficient. As income growth in the BRICS makes them profitable for the innovation, K rises and the overall impact on world returns is a horse race between larger world markets and smaller US markups.

To illustrate, consider when domestic welfare is given by the first-order Taylor approximation $w(\pi)=x_{S}-x_{B} \pi$ and world returns affects innovation according to $P(\Pi)=\Pi^{\gamma}$ where $\gamma \in(0,1)^{7}$. Here, $x_{S}$ represents the "size" of a country (say population or income level) and $x_{B}$ represents the excess burden of providing a given level of profits. Direct algebra then implies that efficient world profits then exceed Nash profits according to

$$
\Pi^{E}=\left(\frac{K+\gamma}{1+\gamma}\right) \Pi^{N a s h}
$$

where $\Pi^{N a s h}=\frac{K \gamma x_{S}}{\left(x_{B}-1\right)(K+\gamma)}$. If there is only one country, the socially efficient and Nash equilibrium profit levels coincide. When more than one country contributes to world profits, $K>1$, world returns are too low in the sense that the efficient level of profits are greater than the Nash equilibrium level. Both the socially efficient and Nash equilibrium levels of profits are increasing in the number of countries K contributing to world returns and the rise in the "benefits" of world innovation (country size $x_{S}$ ) but are decreasing with the "costs" of innovation (the excess burden of taxation in funding the reimbursements $x_{B}$ ). The extent of under provision of world returns, $\Pi^{E}-\Pi^{N a s h}$, rises in the number of countries due to free-riding. Under-provision also rises in the size of each country benefitting from medical innovation, $x_{S}$, but falls in the excess burden of taxation, $x_{B}$. The

7 The range of $P(\cdot)$ is not limited to $[0,1]$ but the form is an approximation chosen for illustrative ease. 
under-provision occurs because each country fails to consider the external benefit of profit provision when determining its price setting policies. Consequently, when the benefit of the innovation in other countries falls (from either a decrease in $x_{S}$ or an increase in $x_{B}$ ) or the number of countries decreases, the free riding problem shrinks.

We can allow heterogeneous countries by writing the welfare generated by the innovation in a particular country as a function of domestic demand factors, $x_{k}$, and the country's ownership share of global profits, $s_{k}$ as in

$$
\mathrm{w}\left(\pi_{k} ; s_{k}, x_{k}\right)=c\left(\pi_{k} ; x_{k}\right)+s_{k} \Pi
$$

Here $c\left(\pi_{k} ; x_{k}\right)$ reflects the decreasing consumer welfare to the country's population as a function of profit provision. Generalizing the example from above, the vector $x_{k}$ includes both domestic factors that increase the domestic value of the innovation such as population, per capita income, or disease prevalence related to the innovation as well as the cost of raising taxes to reimburse for the innovation. The second component of welfare represents the benefit to domestic owners of the innovation.

Since the reimbursement policy set by each country depends on total world profits, each country's reimbursement policy is a function of other countries reimbursement policies. This is the key international linkage in reimbursement levels. More precisely, totally differentiating the FOC for the privately optimal profit provision with respect to another country's profits $\pi_{k^{\prime}}$ yields

$$
\frac{d \pi_{k}}{d \pi_{k^{\prime}}}=-\frac{P^{\prime \prime}(\Pi)\left[c\left(\pi_{k} ; x_{k}\right)+s_{k} \Pi\right]+P^{\prime}(\Pi)\left[c_{\pi}\left(\pi_{k} ; x_{k}\right)+2 s_{k}\right]}{\left.P^{\prime \prime}(\Pi)\left[c\left(\pi_{k} ; x_{k}\right)+s_{k} \Pi\right]+2 P^{\prime}(\Pi)\right)\left[c_{\pi}\left(\pi_{k} ; x_{k}\right)+s_{k}\right]+P(\Pi) c_{\pi \pi}\left(\pi_{k} ; x_{k}\right)}
$$

It can be shown that under the maintained regularity conditions profit provisions are "strategic substitutes" in the sense that ${ }^{8}$

\footnotetext{
${ }^{8}$ Sufficient but not necessary conditions for profits provisions being strategic substitutes are that $P(\Pi)$ is increasing and concave in total profits, $c\left(x_{k}, \pi_{k}\right)$ is decreasing and concave in profits, and $c_{\pi}\left(x_{k}, \pi_{k}\right)+2 s<0$. The last assumption holds trivially provided no countries profit share exceeds 0.50 as the marginal cost of profit provision, in terms of profits, is greater than 1 .
} 


$$
-1 \leq \frac{d \pi_{k}}{d \pi_{j}} \leq 0
$$

If one country's reimbursement policy raises its contribution to world returns, other countries respond by reducing their profit levels. However, an increase in Country j's profits leads to less than one for one decrease in Country k's profits such total world profits increase overall.

Figure 1 illustrates the best response functions in a heterogeneous two region case as, say, the US and the BRICS. The Nash equilibrium profit levels are characterized at the point at which the two best response functions intersect. The negative slope of the best response functions in the Figure corresponds to that strategic substitutability of profits; one country prefers to contribute less to world returns the more other countries contribute. The Nash equilibrium provision of profits is less than the socially efficient provision of profits to the northeast of the Nash profits. 


\section{FiguRE 1: BEST RESPONSE FunCTIONS AND EqUILIBRIUM}

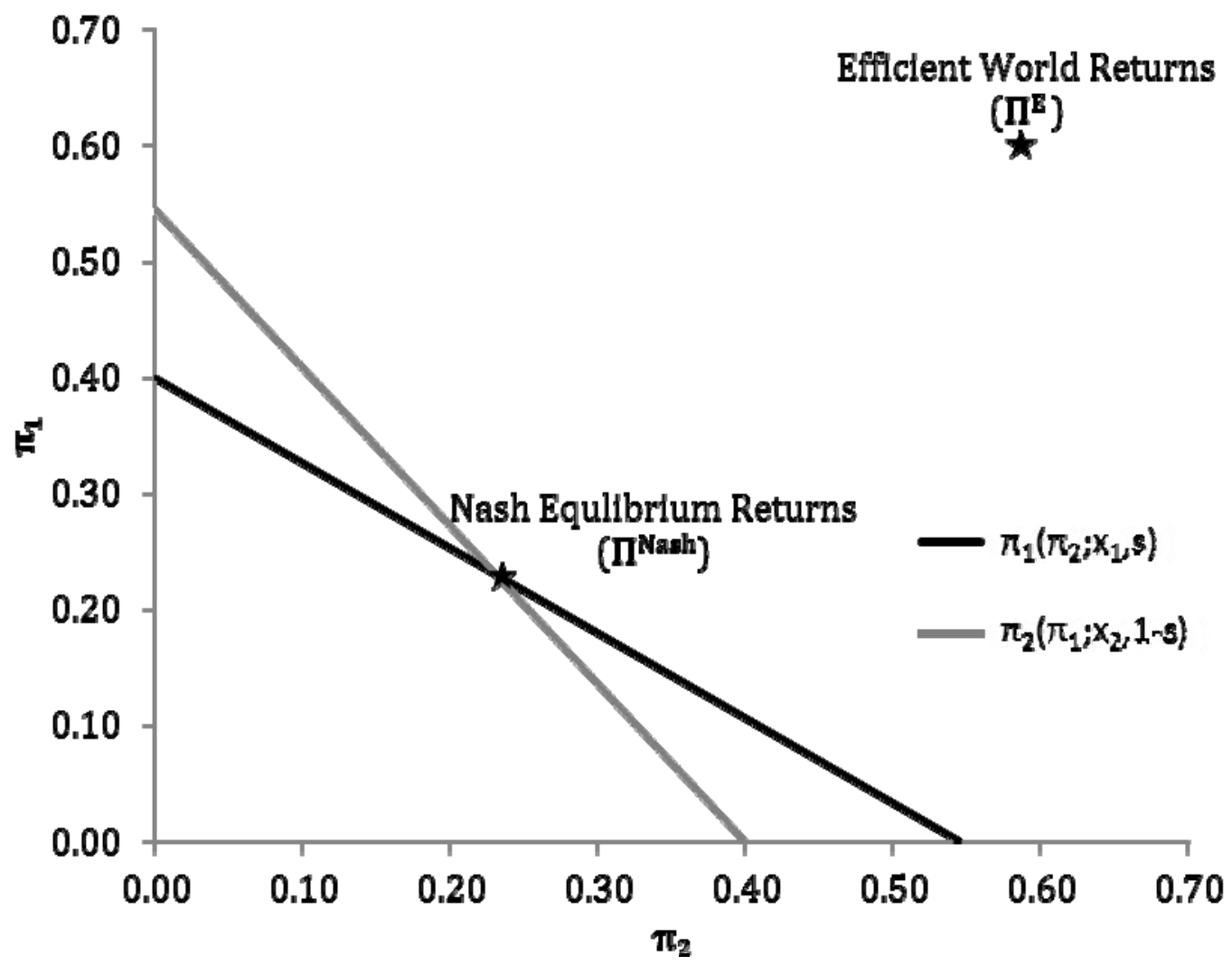

The general result that centrally determined reimbursements are strategic substitutes differs from other predictions without world returns being a public good. First, standard theories of optimal privately determined monopoly pricing across regions imply that the demand elasticity of a given country govern its own price, and thus does not depend on factors of other countries. Second, explanations of national prices based on government monopsony power yield different implications than ours because such explanations imply larger economies have lower, not higher, prices. To illustrate, the fact that the US government has greater centralized bargaining power than smaller European countries but have larger markups in its reimbursements is consistent with the public goods interpretation discussed here.

A second general result is that the concentration of ownership does not affect the efficient level of profits but will affect the Nash equilibrium profits. This follows 
immediately from that aggregate welfare does not depend on the concentration of ownership

$$
\sum_{k=1}^{K}\left[c\left(\pi_{k} ; x_{k}\right)+s_{k} \Pi\right]=\sum_{k=1}^{K} c\left(\pi_{k} ; x_{k}\right)+\Pi
$$

Therefore, the efficient levels of profits are independent of what country owns them.

To illustrate the heterogeneous case, consider again the parametric P-function and the Taylor approximations of welfare $w\left(\pi_{k} ; x_{k}, s_{k}\right)=x_{S k}-x_{B k} \pi_{k}+s_{k} \Pi$ where $x_{B k} \geq 1$. It can then be shown that the best response functions of the two countries are linear functions according to

$$
\begin{aligned}
& \pi_{1}=\delta_{1}+\alpha_{1} \pi_{2} \\
& \pi_{2}=\delta_{2}+\alpha_{2} \pi_{1}
\end{aligned}
$$

The parameters $\delta_{1}$ and $\alpha_{1}$ are functions of $x_{S, 1}, x_{B, 1} s_{1}$ and $\gamma$ while $\delta_{2}$ and $\alpha_{2}$ are similarly functions of $x_{S, 2}, x_{B, 2}, s_{2}$ and $\gamma .9$ The strategic substitutability of profits occurs when the sign of $\alpha_{1}$ and $\alpha_{2}$ are negative which holds under more general regularity conditions ${ }^{10}$. The Nash and efficient levels of profits in the parametric example are ${ }^{11}$

$$
\Pi^{\text {Nash }}=\frac{x_{S 1} x_{B 1}+x_{S 2} x_{B 2}}{\left(1+\frac{1}{\gamma}\right)\left(2 x_{B 1} x_{B 2}-x_{B 1} s_{2}-x_{B 2} s_{1}\right)-x_{B 2} x_{B 1}}, \quad \Pi^{E}=\frac{x_{S 1}+x_{S 2}}{\left(1+\frac{1}{\gamma}\right)\left(x_{B 1}-1\right)}
$$

As before, it is easily shown that profits are under provided; $\Pi^{E} \geq \Pi^{\text {Nash }}$. The parametric example illustrates the more general result that the equilibrium and efficient level of profits are increasing in the welfare benefit of the innovation. Consequently, the equilibrium and efficient levels of profits are increasing in the demand size parameters $x_{S 1}$

${ }^{9}$ Direct derivations imply $\delta_{k}=\frac{x_{S k}}{\left(x_{B k}-s_{k}\right)\left(1+\frac{1}{\gamma}\right)}$ and $\alpha_{k}=\frac{\frac{1}{\gamma}\left(s_{k}-x_{B k}\right)+s_{k}}{\left(x_{B k}-s_{k}\right)\left(1+\frac{1}{\gamma}\right)}$

${ }^{10} \mathrm{~A}$ sufficient but not necessary condition for profits being strategic substitutes in country $\mathrm{k}$ is $x_{B k}>2 s_{k}$. Since $x_{B k} \geq 1$ and $s_{k} \in[0,1]$, this condition is likely benign in practice, especially when the number of countries is expanded.

11 The socially efficient level of profits are calculated, without loss in generality, under the assumption $x_{B 1}<x_{B 2}$ 
and $x_{S 2}$. Similarly, the equilibrium and efficient profit levels are weakly decreasing in the excess profit burden parameters $x_{B 1}$ and $x_{B 2}$. Note that, as discussed, unlike the privately optimal equilibrium level, the efficient level of profits does not depend on the distribution of ownership.

\subsection{The Effect of Domestic Demand Growth}

To assess the impact of growth in world demand for an innovation, consider the FOC for privately optimal profit provision

$$
P^{\prime}(\Pi)\left[c+s_{k} \Pi\right]=-P(\Pi)\left[c_{\pi}+s_{k}\right]
$$

Under the conditions that $c\left(\pi_{k} ; x_{k}\right)$ is decreasing and concave in profits and the additional condition that $c_{\pi x} \geq 0$, it can easily be shown that the best response function is of profit provision is strictly increasing in the demand parameter $x, \frac{d \pi_{k}}{d x_{k}}>0^{12}$. The condition, $c_{\pi x} \geq 0$ states that the social cost of transferring surplus to producers is not increasing in population size; it's cheaper for a larger population to provide the same level of profits to the innovator as per-capita taxes are lower.

As illustrated in Figure 2, consider the scenario where demand growth in Country 1 (say the BRICS) increases from $x_{1}$ to $x_{1}^{\prime}$. For any given level of profits allocated by Country 2 , Country 1 will find it optimal to now set a higher profit level due to its increase in demand. Consequently, Country 1 's best response function, $\pi_{1}\left(\pi_{2} ; x_{1}, s_{1}\right)$, will shift outwards to $\pi_{1}\left(\pi_{2} ; x_{1}^{\prime}, s_{1}\right)$. The unilateral response arrow in the Figure indicates the change in total profits resulting from the demand growth keeping Country 2's profit level fixed. However, since prices are strategic substitutes across countries, both Country 2 and Country 1 strategically respond according to their best response functions such that the equilibrium level of profits shifts to the intersection of the best response curves

12 Total differentiating first order condition (3) with respect to $\pi_{k}$ and $x_{k}$ yields

$$
\frac{d \pi_{k}}{d x_{k}}=-\frac{P(\Pi) c_{\pi x}+P^{\prime}(\Pi) c_{x}}{P(\Pi) c_{\pi \pi}+2 P^{\prime}(\Pi)\left[c_{\pi}+s_{k}\right]+P^{\prime \prime}(\Pi)\left[c+s_{k} \Pi\right]}>0
$$


$\pi_{1}\left(\pi_{2} ; x_{1}^{\prime}, s_{1}\right)$ and $\pi_{2}\left(\pi_{1} ; x_{2}, s_{1}\right)$. Although profits increase overall from $\Pi$ to $\Pi^{\prime}$, the equilibrium response arrow in the Figure indicates how total profits decrease relative to that indicated by the initial unilateral response of Country 1 due to strategic responses of the two countries. The main point is that since prices are strategic substitutes, Country 2 (say the US) "free-rides" off the larger profits provided by Country 1 by lowering its own profit level. Although total profits increase overall, Country 2 sets a lower domestic profit level in the new equilibrium. The strategic profit response by Country 2 will partially but not fully offset the increase in the profits set by Country 1 such that total world profits increase overall.

\section{FiguRE 2: THE EFFECT OF A DOMESTIC DEMAND INCREASE}

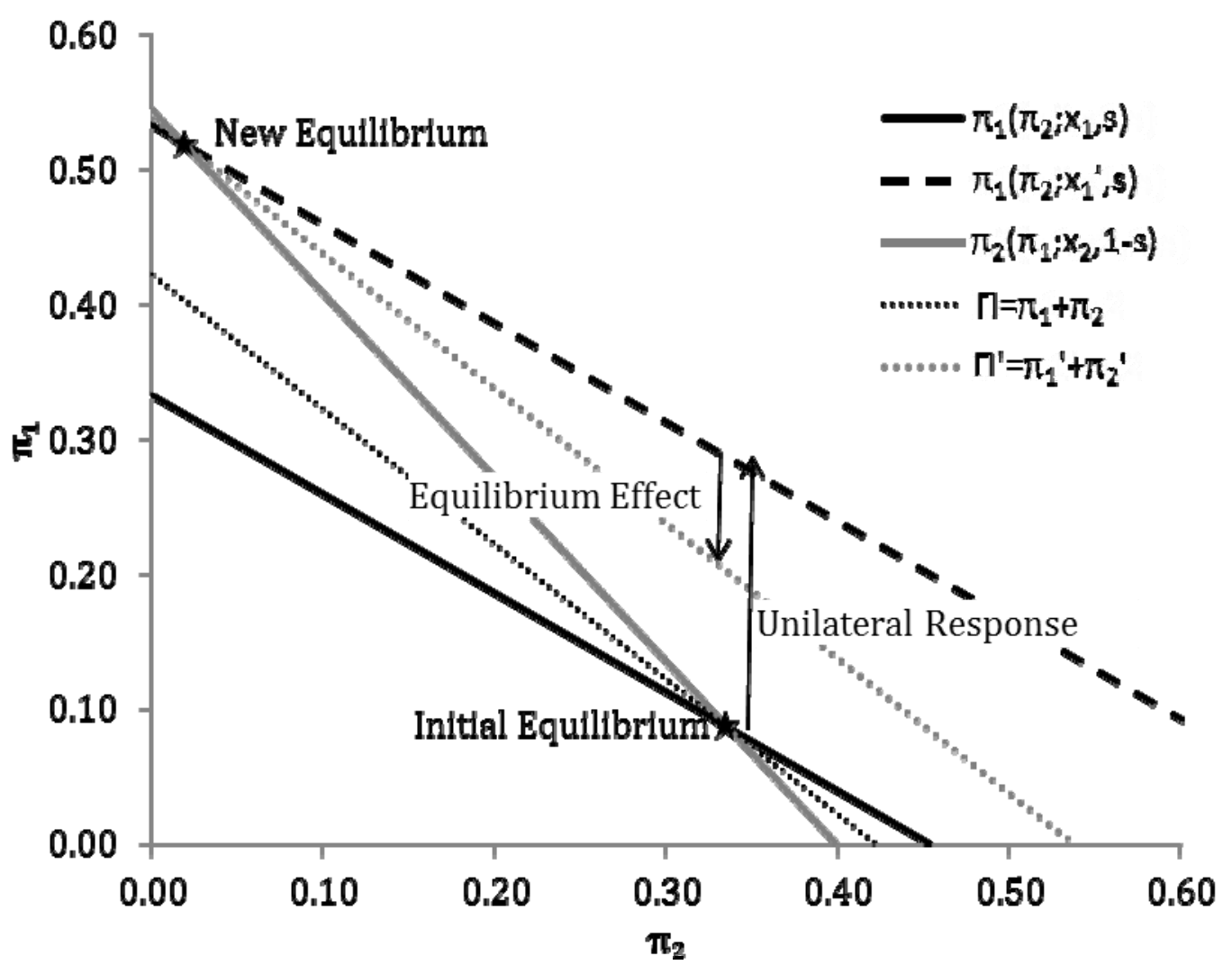

This Figure illustrates two more general implications. First, an increase in domestic demand growth leads to higher domestic profits; $\frac{d \pi_{k}}{d x_{k}}>0$. Second, the strategic profit 
response of other countries will at least partially and could potentially fully offset the entire increase in profits stemming from the domestic demand growth ${ }^{13}$.

$$
0 \leq \frac{d \Pi}{d x_{k}}<\frac{d \pi_{k}}{d x_{k}}
$$

An illustrative case of this offset is that when demand growth in the BRICS occurs, US reimbursements may fall as US becomes one of many providing world returns to innovation.

\subsection{The Effects of Changes in Ownership of Innovative Returns}

Now consider the impact on world returns when changes in ownership of those returns shift across countries. Just as domestic demand growth increases the benefit of the innovation and consequently the country's optimal level of profit provision, the reimbursement level of a country will be a positive function of how much of world profits is owned by that country. Implicitly differentiating the FOC for privately optimal profit provision as before, it can easily be shown that a country's optimal profit level will be a positive function of how much of global profits it owns $; \frac{d \pi_{k}}{d s_{k}}>0^{14}$. However, an increase in one country's profit share implies a decline in another country's share. Consequently, any change in ownership shares $\left(s_{1}, \ldots, s_{K}\right)$ are zero sum and results in that profits are protected more in countries that gain in ownership and less in countries that do not. The implied change in total world returns is

$$
d \Pi=\sum_{k=1}^{K} \frac{d \pi_{k}}{d s_{k}} d s_{k}
$$

${ }^{13}$ For each country $j \neq k$, the impact of an increase in demand in country k results in lower profits in country j, $\frac{d \pi_{j}}{d \pi_{k}} \frac{d \pi_{k}}{d x_{k}}<0$. Consequently, $0 \leq \frac{d \Pi}{d x_{k}}<\frac{d \pi_{k}}{d x_{k}}$.

${ }^{14}$ Totally differentiating the first order condition (3) with respect to $\pi_{k}$ and $s_{k}$ yields

$$
\frac{d \pi_{k}}{d s_{k}}=-\frac{P(\Pi)+P^{\prime}(\Pi) \Pi}{c_{k}^{\prime \prime}\left(\pi_{k}\right) P(\Pi)+2\left[c_{k}^{\prime}\left(\pi_{k}\right)+s_{k}\right] P^{\prime}(\Pi)+\left[c_{k}\left(\pi_{k}\right)+s_{k} \Pi\right] P^{\prime \prime}(\Pi)}>0
$$

The sign of $\frac{d \pi_{k}}{d s_{k}}$ follows from the result that $c s_{k}^{\prime}\left(\pi_{k}\right)+s_{k}<0$ and the concavity of $c_{k}(\cdot)$ and $P(\cdot)$ 
where $\sum_{k=1}^{K} d s_{k}=0$.

Figure 3 illustrates the effect of changes in ownership on world returns for the two country case with shares $(s, 1-s)$. If world returns $\Pi(s)=\pi_{1}(s)+\pi_{2}(1-s)$ is a U-shaped curve in $s$ then concentration in ownership raises world returns but if it is an inverted Ushaped function concentration lowers world returns. If the share of Country 1 rises from $s$ to $s^{\prime}$ the best response function shifts out such that $\pi_{1}\left(\pi_{2}, x_{1}, s^{\prime}\right)>\pi_{1}\left(\pi_{2}, x_{1}, s\right)$. Since the second country own less of the world returns, its best response function shifts inward. The net effect on aggregate profits of a shift in profits is ambiguous and depends on the curvature of the welfare- and probability of discovery function.

FIGURE 3: THE EFFECT OF A CHANGE IN OWNERSHIP

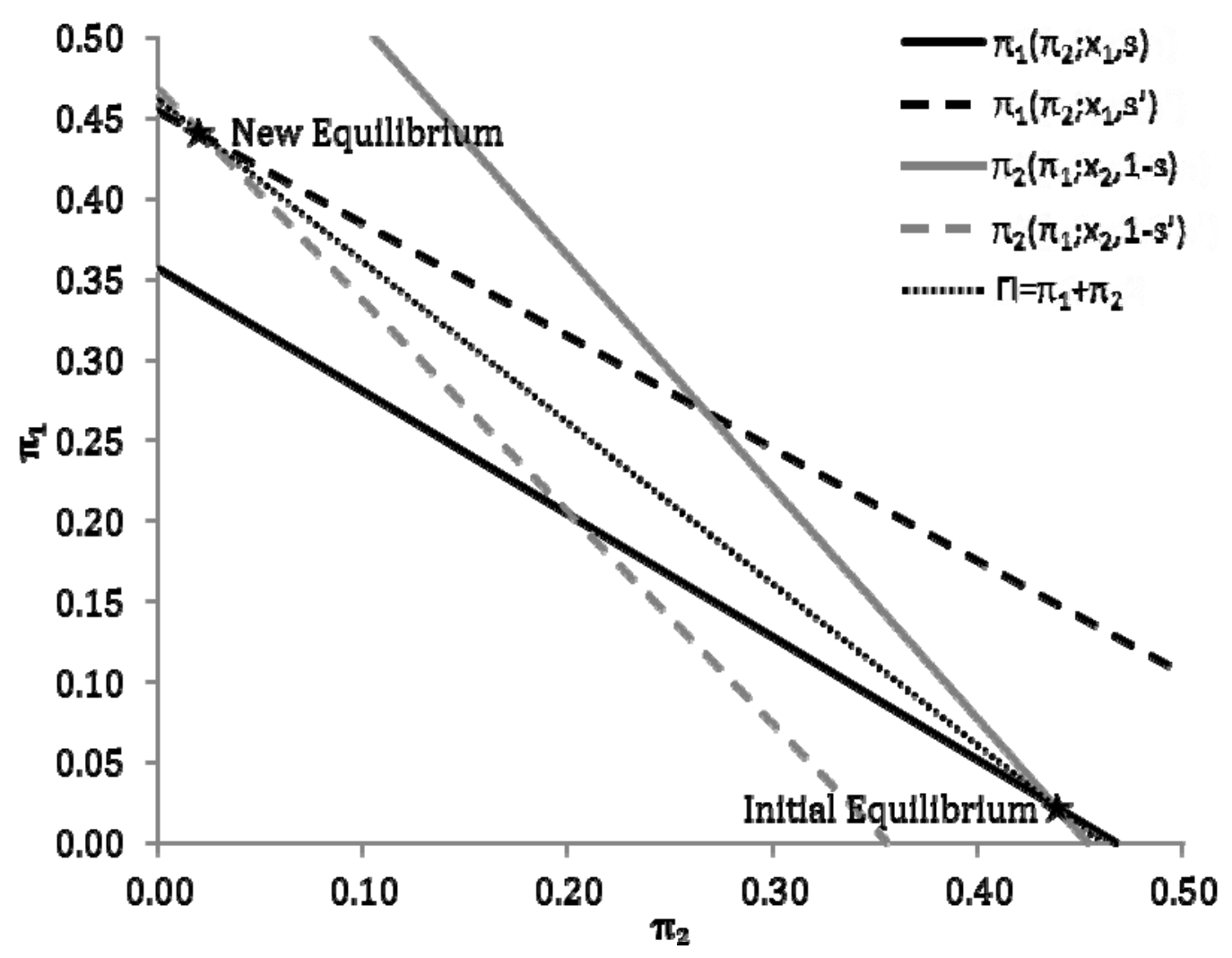

The general point illustrated by the two country example is that changes in ownership shares has indeterminate effects on world returns; $\frac{d \Pi}{d s}$ may be positive or 
negative (The Appendix derives how welfare, $c$, and the probability of innovation, $P(\cdot)$, affect the impact of changes in ownership on world returns).

\section{Section 3: Empirical Analysis}

Our empirical analysis documents the concentration in world health care spending, provides IV-estimates of the strategic substitutability in reimbursement and uses those estimates to assess the degree to which demand growth from the BRICS will impact world innovative returns. The descriptive statistics discussed includes overall health care spending but the estimation is done for reimbursements for pharmaceuticals.

\subsection{World Trends in Concentration of Health Care}

\subsubsection{Trends in Concentration of Health care and Pharmaceutical Expenditures.}

Tables 1 and 2 summarize world health care and pharmaceutical expenditures for the largest countries by health care and pharmaceutical expenditure shares. The health care expenditure, GDP and population data come from the World Bank DataBank. Pharmaceutical expenditure data for OECD and BRICS countries is compiled from the OECD iLibrary and the National Health Accounts database at the World Health Organization ${ }^{15}$ (WHO) respectively ${ }^{16}$. GDP and expenditure data for all of the countries are measured in constant US Dollars (base year=2000).

Even though health economists often debate numbers such as the share of GDP of a country spent on health care, or total spending given per capita by income levels, what matters for innovation incentives are more tied to aggregate world market shares. Our data

\footnotetext{
${ }^{15}$ We would like to thank Richard Liang at the WHO for giving us the BRICS pharmaceutical expenditure time series data.

${ }^{16}$ Note that we use the National Health Accounts and OECD data to compute pharmaceutical expenditure shares rather than the more commonly quoted IMS data. The IMS pharmaceutical data consists of "manufacturers sales to wholesalers and hospitals as well as retail sales of prescription medicine" (World Health Organization 2004). The NHA and OECD data uses a broader definition of health care expenditures than IMS; for example IMS data does not include over the counter medicine sales. Consequently, the NHA data indicates higher pharmaceutical expenditure shares in developing countries than the IMS data.
} 
indicates that currently the US remains the champion of both overall health care and pharmaceutical expenditures, accounting for about $50 \%$ of the world market share for health care and $40 \%$ of world pharmaceutical share. However, despite recent slowdowns, the projected surge in health care expenditures in BRICS and other countries may diminish this concentration in spending in the global health care economy.

Although the health care spending in the US and other developed countries dominates the current level of spending in the BRICS countries, over the period 1995-2010 BRICS overall health care expenditures grew at twice the rate of the world health care expenditures. In terms of its share of total world health expenditures, the BRICS countries growth has come not at the expense of the US but at the expense of the other large countries (i.e. Japan, France and Germany). As the BRICS country with both the largest overall health care sector as well as pharmaceutical sector, China is the driving force behind BRICS health care spending growth in terms of both growth rates and levels. Despite similar population sizes, China spends four times as much on health care than India and China's spending growth continues to outpace India's by $4.60 \%{ }^{17}$.

\footnotetext{
17 Over the period 2005 through 2006, health care expenditures grew at an average annual rate of $12.88 \%$ and $8.28 \%$ in China and India respectively.
} 
TABle 1: World Health CARE EXPENDitures

\begin{tabular}{|c|c|c|c|c|c|c|c|c|c|c|c|c|}
\hline \multirow[b]{2}{*}{ Country } & \multicolumn{2}{|c|}{$\begin{array}{c}\text { Population } \\
\text { (millions) }\end{array}$} & \multicolumn{2}{|c|}{ GDP Per Capita* } & \multicolumn{2}{|c|}{$\begin{array}{c}\text { Income Share } \\
\text { Spent on Health } \\
\text { Care }\end{array}$} & \multicolumn{2}{|c|}{$\begin{array}{c}\text { Total Amt Spent } \\
\text { on Health Care* } \\
\text { (billions) }\end{array}$} & \multicolumn{2}{|c|}{$\begin{array}{c}\text { Expenditure } \\
\text { Share } \\
\text { (\% World Exp.) }\end{array}$} & \multicolumn{2}{|c|}{$\begin{array}{c}\text { World Rank } \\
\text { (Expenditure } \\
\text { Share) }\end{array}$} \\
\hline & 2010 & 1995 & 2010 & 1995 & 2010 & 1995 & 2010 & 1995 & 2010 & 1995 & 2010 & 1995 \\
\hline United States & 309 & 266 & 37,330 & 30,051 & $17.9 \%$ & $13.6 \%$ & 2,066 & 1,085 & $48.0 \%$ & $45.0 \%$ & 1 & 1 \\
\hline Japan & 127 & 125 & 39,972 & 36,177 & $9.5 \%$ & $6.9 \%$ & 483 & 312 & $11.2 \%$ & $13.0 \%$ & 2 & 2 \\
\hline Germany & 82 & 82 & 25,306 & 21,061 & $11.6 \%$ & $10.1 \%$ & 241 & 174 & $5.6 \%$ & $7.2 \%$ & 3 & 3 \\
\hline France & 65 & 60 & 22,758 & 19,478 & $11.9 \%$ & $10.4 \%$ & 176 & 120 & $4.1 \%$ & $5.0 \%$ & 4 & 4 \\
\hline United Kingdom & 62 & 58 & 28,034 & 20,724 & $9.6 \%$ & $6.8 \%$ & 168 & 82 & $3.9 \%$ & $3.4 \%$ & 5 & 5 \\
\hline China & 1,338 & 1,205 & 2,426 & 658 & $5.1 \%$ & $3.5 \%$ & 165 & 28 & $3.8 \%$ & $1.2 \%$ & 6 & 10 \\
\hline Italy & 60 & 57 & 18,943 & 17,671 & $9.5 \%$ & $7.3 \%$ & 109 & 73 & $2.5 \%$ & $3.0 \%$ & 7 & 6 \\
\hline Canada & 34 & 29 & 25,575 & 20,170 & $11.3 \%$ & $9.0 \%$ & 99 & 54 & $2.3 \%$ & $2.2 \%$ & 8 & 7 \\
\hline Brazil & 195 & 162 & 4,717 & 3,606 & $9.0 \%$ & $6.7 \%$ & 83 & 39 & $1.9 \%$ & $1.6 \%$ & 9 & 8 \\
\hline Spain & 46 & 39 & 15,458 & 12,049 & $9.5 \%$ & $7.4 \%$ & 68 & 35 & $1.6 \%$ & $1.5 \%$ & 10 & 9 \\
\hline Korea, Rep. & 49 & 45 & 16,219 & 9,548 & $6.9 \%$ & $3.9 \%$ & 56 & 17 & $1.3 \%$ & $0.7 \%$ & 11 & 17 \\
\hline Netherlands & 17 & 15 & 26,553 & 20,429 & $11.9 \%$ & $8.3 \%$ & 53 & 26 & $1.2 \%$ & $1.1 \%$ & 12 & 11 \\
\hline Australia & 22 & 18 & 25,249 & 18,627 & $8.7 \%$ & $7.2 \%$ & 49 & 24 & $1.1 \%$ & $1.0 \%$ & 13 & 12 \\
\hline Mexico & 113 & 92 & 6,105 & 4,832 & $6.3 \%$ & $5.1 \%$ & 44 & 23 & $1.0 \%$ & $1.0 \%$ & 14 & 13 \\
\hline India & 1,225 & 964 & 795 & 367 & $4.1 \%$ & $4.3 \%$ & 39 & 15 & $0.9 \%$ & $0.6 \%$ & 15 & 20 \\
\hline Russia & 142 & 148 & 2,927 & 1,618 & $5.1 \%$ & $5.3 \%$ & 21 & 13 & $0.5 \%$ & $0.5 \%$ & 22 & 22 \\
\hline South Africa & 50 & 39 & 3,753 & 2,960 & $8.9 \%$ & $7.5 \%$ & 17 & 9 & $0.4 \%$ & $0.4 \%$ & 27 & 25 \\
\hline World & 6,894 & 5,715 & 6,006 & 4,788 & $10.4 \%$ & $8.8 \%$ & 4,301 & 2,410 & $100.0 \%$ & $100.0 \%$ & & \\
\hline
\end{tabular}

TABle 2: World Pharmaceutical Expenditures

\begin{tabular}{|c|c|c|c|c|c|c|c|c|c|c|c|c|}
\hline \multirow[b]{2}{*}{ Country } & \multicolumn{2}{|c|}{$\begin{array}{c}\text { Population } \\
\text { (millions) }\end{array}$} & \multicolumn{2}{|c|}{ GDP Per Capita* } & \multicolumn{2}{|c|}{$\begin{array}{c}\text { Income Share } \\
\text { Spent on Health } \\
\text { Care }\end{array}$} & \multicolumn{2}{|c|}{$\begin{array}{l}\text { Share of Health } \\
\text { Care Exp. Spent } \\
\text { on Pharm. }\end{array}$} & \multicolumn{2}{|c|}{$\begin{array}{l}\text { Total Amt Spent } \\
\text { on Pharm.* } \\
\text { (billions) }\end{array}$} & \multicolumn{2}{|c|}{$\begin{array}{c}\text { Expenditure } \\
\text { Share** } \\
\text { (\% World Exp.) }\end{array}$} \\
\hline & 2008 & 1995 & 2008 & 1995 & 2008 & 1995 & 2008 & 1995 & 2008 & 1995 & 2008 & 1995 \\
\hline United States & 304 & 266 & 38,209 & 30,051 & $16.5 \%$ & $13.6 \%$ & $12.1 \%$ & $8.4 \%$ & 232 & 91 & $38.6 \%$ & $30.1 \%$ \\
\hline Japan & 128 & 125 & 40,433 & 36,177 & $8.5 \%$ & $6.9 \%$ & $19.4 \%$ & $22.2 \%$ & 85 & 69 & $14.2 \%$ & $22.9 \%$ \\
\hline China & 1,325 & 1,205 & 2,033 & 658 & $4.6 \%$ & $3.5 \%$ & $42.7 \%$ & $54.2 \%$ & 53 & 15 & $8.9 \%$ & $5.0 \%$ \\
\hline Germany & 82 & 82 & 25,620 & 21,061 & $10.7 \%$ & $10.1 \%$ & $15.0 \%$ & $12.8 \%$ & 34 & 22 & $5.6 \%$ & $7.3 \%$ \\
\hline France & 64 & 60 & 23,366 & 19,478 & $11.2 \%$ & $10.4 \%$ & $16.4 \%$ & $15.0 \%$ & 28 & 18 & $4.6 \%$ & $6.0 \%$ \\
\hline Italy & 60 & 57 & 19,903 & 17,671 & $9.0 \%$ & $7.3 \%$ & $18.1 \%$ & $20.7 \%$ & 19 & 15 & $3.2 \%$ & $5.0 \%$ \\
\hline United Kingdom & 61 & 58 & 29,107 & 20,724 & $8.9 \%$ & $6.8 \%$ & $11.8 \%$ & $15.3 \%$ & 19 & 13 & $3.1 \%$ & $4.2 \%$ \\
\hline Brazil & 192 & 162 & 4,479 & 3,606 & $8.3 \%$ & $6.7 \%$ & $24.6 \%$ & $16.7 \%$ & 17 & 6 & $2.9 \%$ & $2.1 \%$ \\
\hline Canada & 33 & 29 & 26,102 & 20,170 & $10.3 \%$ & $9.0 \%$ & $17.0 \%$ & $13.9 \%$ & 15 & 7 & $2.5 \%$ & $2.5 \%$ \\
\hline India & 1,191 & 964 & 689 & 367 & $4.0 \%$ & $4.3 \%$ & $44.2 \%$ & $55.4 \%$ & 15 & 8 & $2.4 \%$ & $2.8 \%$ \\
\hline Spain & 46 & 39 & 16,251 & 12,049 & $9.0 \%$ & $7.4 \%$ & $18.7 \%$ & $19.2 \%$ & 12 & 7 & $2.1 \%$ & $2.2 \%$ \\
\hline Mexico & 111 & 92 & 6,327 & 4,832 & $5.9 \%$ & $5.1 \%$ & $28.3 \%$ & $\# \mathrm{~N} / \mathrm{A}$ & 12 & 0 & $1.9 \%$ & $0.0 \%$ \\
\hline Korea, Rep. & 49 & 45 & 15,350 & 9,548 & $6.5 \%$ & $3.9 \%$ & $23.2 \%$ & $23.6 \%$ & 11 & 4 & $1.9 \%$ & $1.3 \%$ \\
\hline Australia & 21 & 18 & 25,246 & 18,627 & $8.7 \%$ & $7.2 \%$ & $14.6 \%$ & $12.2 \%$ & 7 & 3 & $1.2 \%$ & $1.0 \%$ \\
\hline Belgium & 11 & 10 & 25,100 & 19,940 & $10.0 \%$ & $8.5 \%$ & $16.4 \%$ & $18.1 \%$ & 4 & 3 & $0.7 \%$ & $1.0 \%$ \\
\hline South Africa & 49 & 39 & 3,796 & 2,960 & $8.6 \%$ & $7.5 \%$ & $25.1 \%$ & $28.3 \%$ & 4 & 2 & $0.7 \%$ & $0.8 \%$ \\
\hline Russia & 142 & 148 & 3,044 & 1,618 & $4.8 \%$ & $5.3 \%$ & $18.8 \%$ & $18.9 \%$ & 4 & 2 & $0.7 \%$ & $0.8 \%$ \\
\hline World & 6,737 & 5,715 & 6,026 & 4,788 & $9.8 \%$ & $8.8 \%$ & $\# \mathrm{~N} / \mathrm{A}$ & $\# \mathrm{~N} / \mathrm{A}$ & 601 & 302 & $100.0 \%$ & $100.0 \%$ \\
\hline
\end{tabular}

Notes on Tables 1 and 2:

- $\quad(*)$ Measured in 2000 constant US Dollars.

- $\quad\left({ }^{* *}\right)$ World totals calculated using all available data which is limited to BRICS and OECD countries.

- GDP and population data come from the World Bank DataBank.

- Pharmaceutical expenditure data for OECD and BRICS countries is compiled from the OECD iLibrary and WHO National Health Accounts respectively. 
Contrasting Table 1 relative to Table 2 suggests that emerging economies devote a higher portion of total health expenditures to pharmaceuticals than developed countries. BRICS health care spending is concentrated in pharmaceuticals with over $40 \%$ of total health expenditures spent on drugs in India and China relative to $12 \%$ in the US. As a result, the BRICS countries account for less than $8 \%$ of total world health expenditures but more than $15 \%$ of total world pharmaceutical expenditures. Thus, due to the relative size their pharmaceutical markets, the BRICS countries may play a larger role in spurring the innovation of pharmaceuticals versus non-pharmaceutical medical products and the physician and hospital services tied to those products. However, the non-pharmaceutical related health care market in the BRICS countries is growing faster relative to the size of their pharmaceutical markets.

\subsubsection{Supply Trends}

Our analysis implied that ownership shares across countries drives actual, although not efficient, reimbursement policy. As country-specific ownership shares of pharmaceutical- and other health care companies are not available given existing data sources, we use pharmaceutical production data ${ }^{18}$. In particular, we use pharmaceutical production data to proxy for a country's attention to supply side issues of supporting innovative returns. Figure 4 displays the value ${ }^{19}$ of pharmaceutical production in the US, Japan, China, India and Russia over the past thirty years as reported in the 2006 and 2010 online editions of the UN Industrial Statistics Database ${ }^{20}$

\footnotetext{
${ }^{18}$ Data on firm ownership across countries is to our knowledge unavailable. Ideally we would like to know the percentage of company XYZ that owned by US citizens, Chinese citizens, etc. for each firm and country.

19 Production is valued either in terms of factor cost, which excludes all indirect production taxes but includes production subsidies, or in terms of producer prices, which includes indirect production taxes but excludes production subsides.

20 The Database does not contain production data for the countries in BRICS not represented in graph.
} 


\section{Figure 4: Pharmaceutical Production}

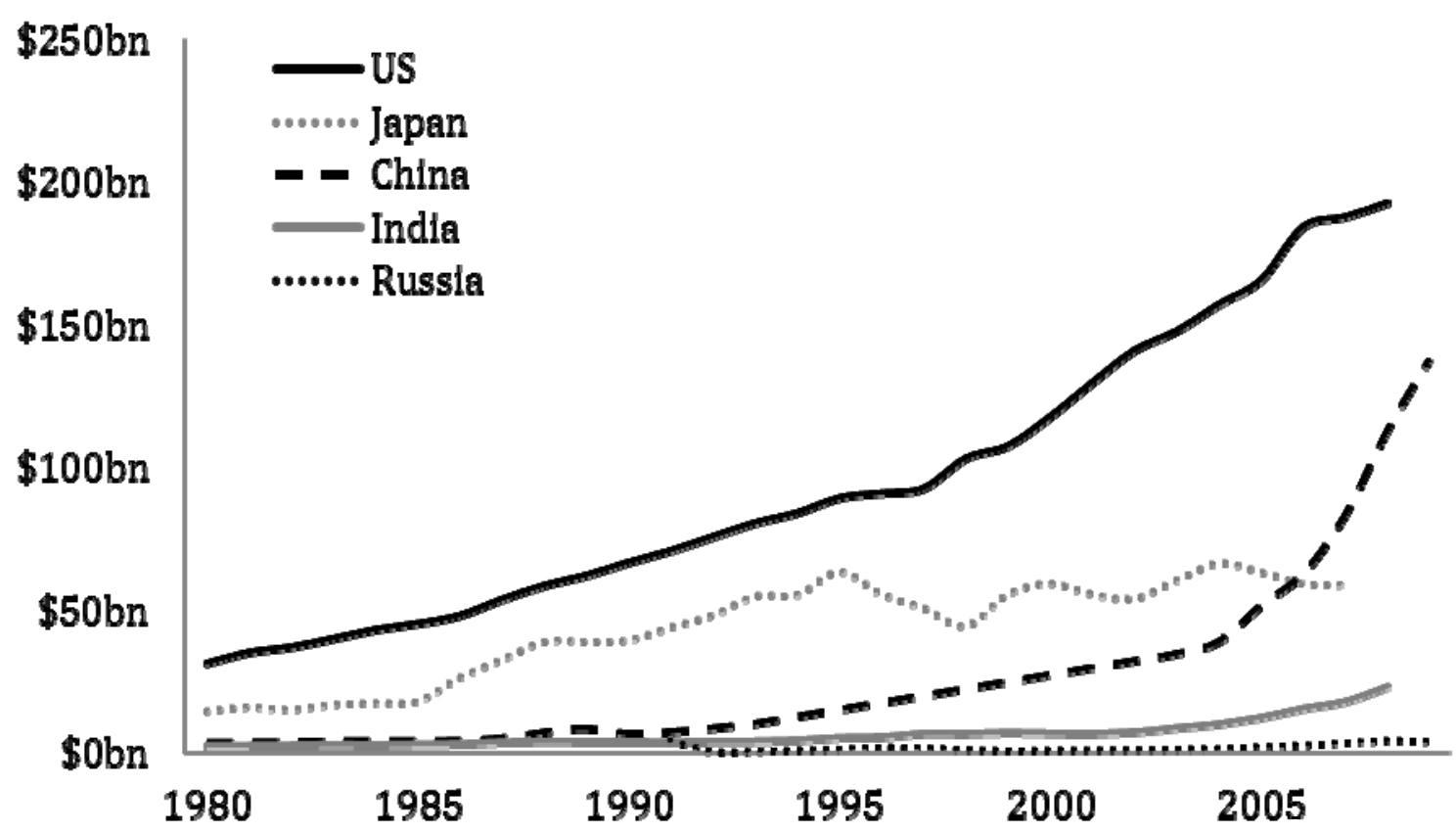

Notes on Figure 4:

- The data is from the 2006, 2010 and online editions of the UN Industrial Statistics Database. Data from the online and 2010 edition reflects ISIC code 2423 "Pharmaceuticals, medicinal chemicals, etc."

- Data from the 2006 edition reflects ISIC 352 "Other chemicals" and is scaled by 1/2 to reflect that ISIC 352 includes non-pharmaceutical chemical production. The scaling factor was determined by the average ratio of ISIC 2423 to ISIC 352 for the years/countries in which data overlapped between the 2006 and 2010 data sets.

- For the online data, output was converted into USD using annual forex data from http://www.oanda.com/.

- Missing data points were linearly interpolated.

Over the period 1990 to 2008, pharmaceutical production in China and India increased by a multiples of 15 and 6 respectively. During the same period pharmaceutical production in the US increased by a multiple of 3 while production in Japan and Russia remained relatively flat. Our analysis predicts a continued growth in the Chinese and Indian production should put upward reimbursement pressure in those countries, while putting downward pressure on reimbursements in other countries. 


\subsection{Empirical Analysis of Strategic Substitutability}

\subsubsection{Specification}

We consider an empirical specification that allows us to test for the strategic substitutability of reimbursements as well as the importance of supply and demand changes on reimbursement policy. Due to the availability of data, our model focuses on the reimbursements for pharmaceutical products rather than the more general problem of profit provision for other medical products and services. The specialized version of the previous analysis considered concerns when each country faces the optimal price setting decision:

$$
\max _{p_{k}} P\left(\sum_{j=1}^{K} \pi_{j}\left(p_{j}, x_{j}\right)\right)\left[c\left(\pi_{k}\left(p_{k} ; x_{k}\right) ; x_{k}\right)+s_{k} \sum_{j=1}^{K} \pi_{j}\left(p_{j}, x_{j}\right)\right]
$$

where the profits contributed by a given country $\pi_{k}\left(p_{k}, x_{k}\right)$ is an increasing function of its own price.

This price setting problem and the profit provision problem discussed earlier are direct analogs. The first order condition corresponding to the country's optimal pricing problem is the direct analog of the first order corresponding to the optimal profit provision policy. Just as with profit provision, a country's optimal price will be a function of its demand factors, profit share and aggregate profits. The preceding comparative static result that profits are strategic substitutes across countries applies to prices such that a country's optimal price level is decreasing in total world returns. Similarly, a country's optimal price level is increasing in its profit share. However, even though a country's optimal profit level is increasing in demand factors $(x)$, its corresponding optimal price may not be increasing in demand factors. The key intuition behind the result is that since profit is function of both price and quantity , an increase in a country's size or income could lead to a higher domestic profit level even if the country chooses to lowers its own price level. This occurs 
when the quantity increase from the larger "size" of the country more than offsets any possible reduction in markups 21 .

This price setting case lends itself to estimation of the following linearized specification of strategic interaction

$$
p_{k, t}=\delta_{k}+\alpha \sum_{j \neq k} q_{j, t} p_{j, t}+\theta \widetilde{s}_{k, t}+\beta x_{k, t}+\varepsilon_{k, t}
$$

where $p_{k, t}$ is the price of pharmaceuticals set by country $\mathrm{k}$ at time $\mathrm{t}, \widetilde{s}_{k, t}$ is pharmaceutical production in country $\mathrm{k}$ at time $\mathrm{t}$ (proxying for ownership shares), $\delta_{k}$ are country fixed effects (an element of the x-vector affecting country specific welfare), $q_{j, t}$ are quantity weights, and $x_{k, t}$ is a vector of the demand factors that drive domestic pricing but not foreign pricing of country $\mathrm{k}$ at time $\mathrm{t}$. The term $q_{j, t} p_{j, t}$ corresponds to the pharmaceutical revenues in country $j$ at time $t$. If the marginal production costs are negligible, the empirical model (eq. 5) is analogous to the model

$$
p_{k, t}=\delta_{k}+\alpha \sum_{j \neq k} \pi_{j, t}+\theta \widetilde{s}_{k, t}+\beta x_{k, t}+\varepsilon_{k, t}
$$

Equations (5) and (6) are thus the linearized best response function corresponding to the country's optimal profit provision discussed earlier. We estimate a country's best response as per equation (5) rather than equation (6) due to the data availability issues regarding accurate revenue and profit data.

Our analysis implies that prices are strategic substitutes, which corresponds to the parameter restriction $\alpha<0$. The analysis also predicts that countries earning a greater

${ }^{21}$ In particular, the key sufficient condition we used to show that profits are increasing domestic in demand factors in section 2.1 is $c_{\pi x} \geq 0$. The necessary condition to show that prices are increasing in domestic demand factors is much stronger and less tenable and intuitive condition that

$$
P^{\prime \prime}(\Pi) \pi_{x}[c+s \Pi]+P^{\prime}(\Pi)\left[c_{\pi} \pi_{x}+c_{x}+s \pi_{x}\right]+P^{\prime}(\Pi) \pi_{x}\left[c_{\pi}+s\right]+P(\Pi)\left[c_{\pi \pi} \pi_{x}+c_{\pi x}\right]>0
$$

The condition implies that an increase in demand factors increases the marginal benefit of increasing price by a larger amount than it increases the marginal cost of increasing price. 
producer surplus from the pharmaceutical industry will set higher prices. Although we do not observe the global distribution of pharmaceutical profits, we use pharmaceutical production as a proxy for pharmaceutical profits. Also, countries may value domestic pharmaceutical production for other reasons, such as labor demand. In that vein, the analysis predicts that countries with greater pharmaceutical production will set higher prices; $\theta>0$. Further, we expect the two demand factors population and GDP per capita to be relevant price setting factors. Although our theory suggests that profits will be increasing in the two demand factors population and GDP per capita, prices could be decreasing in either population and/or GDP per capita as quantity may rise more than markups fall.

Two primary econometric issues arise when estimating equation (5): the simultaneity of prices and the endogeneity of production. The optimal price set by country $\mathrm{k}$ is a function of the weighted sum of all other countries prices $\sum_{k \neq i} q_{j, t} p_{j, t}$. Similarly, the optimal price set by each other country $j, j \neq k$, included the weighted sum, $\sum_{j \neq k} q_{j, t} p_{j, t}$ is also a function of $p_{k, t}$. Consequently, equation (5) suffers from the classic simultaneity problem. Any simple regression of $p_{k, t}$ on $\sum_{j \neq k} q_{j, t} p_{j, t}$ would result in biased estimates due to the endogeneity of the term $\sum_{j \neq k} q_{j, t} p_{j, t}$. We implement an instrumental variables strategy to circumvent the endogeneity problem and recover country k's best response function. Following our theoretical discussion in Section 2 on the effects of domestic demand shifts ${ }^{22}$ we use, as instruments, the covariates of other countries, $X_{-k, t}$, weighted by the same weights as specified in equation (5) lagged by one year $q_{t-1}{ }^{23}$. We use the quantity weights from the previous as opposed to the current period to avoid further endogeneity problems. The instrumental variables strategy relies on using exogenous variation in the covariates of other countries, $X_{-k, t}$, to trace out country k's best response function. The two country discussion of domestic demand shifts presented in Figure 2 of

\footnotetext{
${ }^{22}$ See also some related work in urban end environmental economics Figlio et al. 1999; Fredriksson and Millimet 2002.

${ }^{23}$ See Brueckner (2003) for an overview of empirical studies on strategic interaction among governments.
} 
Section 2.1 illustrates the main concept behind our IV strategy. Holding all else equal, we use the exogenous variation in Country 1's demand covariates, $x_{1}$, to trace out the best response function of Country 2 (and vice versa).

The validity of our IV estimate hinges on our instrument satisfying so called relevancy and exogeneity conditions. The relevancy condition of instrumental variables requires that the instrument, the weighted demand characteristics of other countries ( $X_{-k, t}$, is correlated with the endogenous variable, $\sum_{j \neq k} q_{j, t} p_{j, t}$, conditional on $\delta_{k}, x_{k, t}$ and $\widetilde{s}_{k, t}$. We test for relevancy in a standard manner by computing and analyzing the F-statistics from the first stage regressions and Shea's partial $R^{2}$ measure (1997). Each measure provides evidence suggesting that the relevancy condition holds.

The exogeneity condition requires that our instrument is uncorrelated with unobserved error term. Specifically, this requires that the unobserved determinants of pharmaceutical prices (such as say preferences or costs) are uncorrelated with weighted demand characteristics of other countries. Since the number of instruments exceeds the number of endogenous variables, we empirically test the exogeneity condition as per Sargan (1958) and fail to reject the null hypothesis of exogeneity in our fully specified model.

Relating to the exogeneity condition, the IV method should also abate concerns about potentially omitted variables in equation (5). It is reasonable to assume that equation (5) does not contain the entire relevant price setting factors. For example one might think that equation (5) omits potentially important demand and supply control variables such as, most obviously, production costs. If pharmaceutical costs and/or preferences are positively correlated across countries, one might expect the weighted sum of other countries prices, $\sum_{j \neq k} q_{j, t} p_{j, t}$, conditional on $\delta_{k}, x_{k, t}$ and $\widetilde{s}_{k, t}$ to be positively correlated with the error term, $\varepsilon_{k, t}$, which would result in our OLS estimates of $\alpha$ being asymptotically biased upward such that plim $\hat{\alpha}^{O L S}>\alpha$. Hence, the potential omitted variables and endogeneity problem could result in OLS estimates of $\alpha$ suggesting that prices are strategic complements across countries when they are in fact strategically 
substitutes. Provided that the omitted variables are uncorrelated with our set of instruments, the observed demand characteristics of other countries, our IV estimates will correct for this asymptotic bias.

The final empirical issue involves the endogeneity of pharmaceutical production. Unobserved domestic demand factors could potentially be positively correlated with quantity of pharmaceuticals produced which would results in biased estimates of $\theta$. We correct for the endogeneity problem again using instrumental variables using lagged production as an instrument for current production similar to the strategy employed by Villas-Boas and Winer (1999). The instrument is valid provided that domestic production is correlated over time but previous pharmaceutical production is uncorrelated with current demand shocks. As discussed previously, we again empirically assess the validity of the instrument and find evidence suggesting that the exogeneity and relevancy conditions hold.

\subsubsection{Data}

We estimate equation (5) using pharmaceutical data from a balanced panel of 21 OECD countries over the period 1999 to $2008^{24}$. The 21 countries accounted for roughly over $80 \%$ of pharmaceutical spending in 1999. The pharmaceutical price index is constructed from several sources. We use CPI data from the BLS, Eurostat, Japan and Statistics Canada to measure within country pharmaceutical price movements across time by using the ratio of pharmaceutical price index relative to consumer price index (all goods) as suggested by Golec and Vernon (2006). Next, we are then able to scale the relative pharmaceutical price levels across countries in the year 2005 using OECD relative pharmaceutical price data ${ }^{25}$. Figure 5 below indicates the price movements of the US, Japan, France, Germany and the UK over the period 1996 to 2010. The remaining data used in estimation are summarized in Table 3.

\footnotetext{
${ }^{24}$ Although the full data set spans 26 countries over 1996-2010, we trim the data set to allow for a balanced panel. As a robustness check we use the full unbalanced data set.

25 The relative pharmaceutical price data is from OECD Health Policy Studies (2008).
} 
Due to data constraints, our pharmaceutical price index may be a noisy measure of pharmaceutical prices. We use country specific pharmaceutical and consumer price indices to capture the within country pharmaceutical price movements across time by looking at changes in the ratio of pharmaceutical prices relative to all consumer prices. The methodology used by the BLS, Eurostat, Japan and Statistics Canada to calculate pharmaceutical and consumer price levels varies across the four sources which could create inconsistencies in our price indices. The pharmaceutical price levels are first scaled across countries using OECD relative pharmaceutical price data and then re-scaled using the Danzon and Furukawa (2003) data set as a robustness check ${ }^{26}$. The OECD pharmaceutical price data is in terms of real purchasing power parity which may not be the applicable measure for our context. However, as long as the measurement error in our pharmaceutical price variable is orthogonal to our instrument, the demand characteristics of other countries, our estimates will not suffer from any measurement error related bias.

${ }^{26}$ The OECD relative pharmaceutical price index reflects final retail prices, or in other words the total social cost of pharmaceuticals, which includes wholesaler and pharmacy markups and VAT rates. Danzon and Furukawa's index (Discounted All Molecule-Indication) reflects manufacture price levels and which excludes both wholesaler and pharmacy markups. 
Figure 5: Real Pharmaceutical Prices

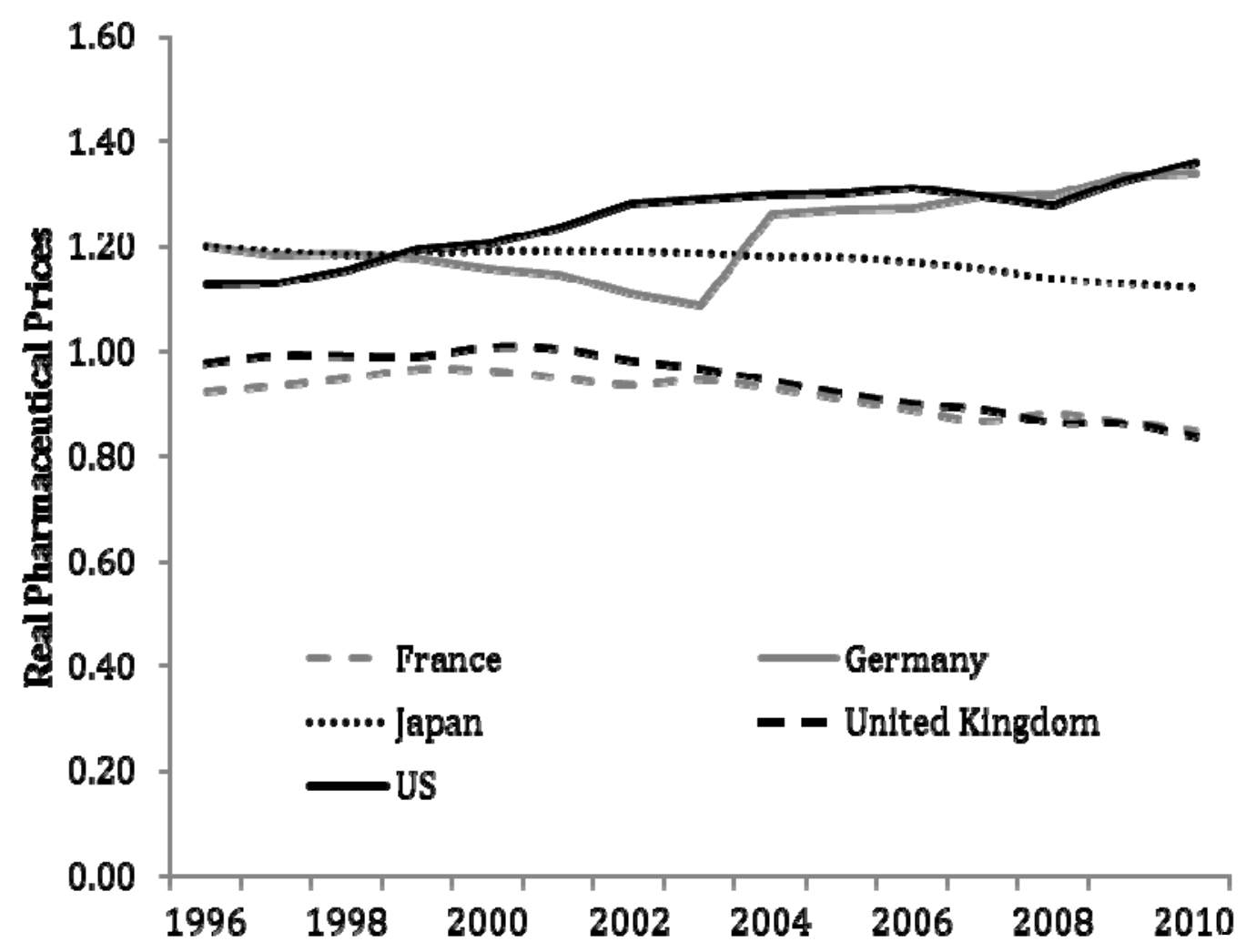

TABLE 3: Summary STATISTICS

\begin{tabular}{|c|c|c|c|c|c|}
\hline Variable & Obs & Mean & Std.Dev. & Min & Max \\
\hline Real Pharm. Price Index $\left(p_{i, t}\right)$ & 210 & 1.08 & 0.21 & 0.57 & 1.60 \\
\hline $\begin{array}{l}\text { Pharmaceutical Production }\left(\widetilde{s}_{i, t}\right) \\
\text { (10 billion, USD } 2005)\end{array}$ & 144 & 1.96 & 3.39 & 0.02 & 18.65 \\
\hline $\begin{array}{l}\text { GDP Per Capita } \\
\text { (10 thousands, USD 2005) }\end{array}$ & 210 & 2.60 & 1.06 & 0.53 & 5.63 \\
\hline $\begin{array}{l}\text { Population } \\
\text { (100 million) }\end{array}$ & 210 & 0.40 & 0.65 & 0.003 & 3.04 \\
\hline
\end{tabular}

Notes on Figure 5 and Table 3:

- The Real Pharmaceutical Price index is scaled across countries using OECD relative prices as discussed in Section 3.2.2. 
The health care expenditure, GDP and population data comes from the World Bank Databank while the pharmaceutical expenditure data is compiled from the OECD iLibrary. Pharmaceutical expenditures are computed as the product of: pharmaceutical expenditures as a percentage of total health expenditures; total health expenditures as a percentage of GDP; and real GDP (measured in constant USD) ${ }^{27}$.

The production data comes from comes from the UN Industrial Statistics Database (INDSTAT4 2010 ISIC Rev. 3). Production data is available for only 19 out of the 21 countries discussed previously over the period 1999-2006 28 . One potential issue is that how production is valued across countries potentially differs in terms of whether it is valued at producer's prices or factor prices. This measurement error could result in potential bias. Further, it is likely that the measurement error is correlated across time; consequently our instrumental variables strategy does little to mitigate this issue. Provided that the measurement error is classical, our estimate of $\theta$ may suffer from an attenuation bias.

\subsubsection{Estimation Results}

Table 4 indicates our estimation results corresponding to equation (5). Columns (1)(3) report the results of the regression of pharmaceutical prices on the weighted sum of other prices, $\sum_{j \neq k} q_{j, t} p_{j, t}$, GDP per capita, and population. Pharmaceutical output is included as an additional regressor in the specifications reported in columns (4)-(6). We report specifications with and without pharmaceutical output as including pharmaceutical output limits the size and time span of our dataset. In columns (4) and (6), we instrument for the weighted sum of prices, $\sum_{j \neq k} q_{j, t} p_{j, t}$ using the weighted sum of other country

\footnotetext{
27 Data on pharmaceutical expenditures as a percentage of total health expenditures is linearly interpolated for Portugal and the United Kingdom in the year 1999, the Netherlands in years 2003-2006, and Belgium in years 1999-2002.

${ }^{28}$ Production data is unavailable for Japan and the United Kingdom in the year 2006, Slovakia and Belgium in the year 2002, Ireland in the year 2004, and Canada in years 2004-2006. These data points are treated as missing observations in specifications (4)-(6), but are still included in the terms $\sum_{j \neq k} q_{j, t} p_{j, t}$ when production data is unavailable.
} 
population and GDP per capita covariates. We also instrument for pharmaceutical output using lagged pharmaceutical output in column (6).

The results of all six specifications indicate that pharmaceutical prices across countries are strategic substitutes. The coefficient, $\hat{\alpha}$, for the weighted sum of other countries prices, is negative and statistically significant at the either $5 \%$ or $1 \%$ level in each regression. The results from column (1) can be interpreted as follows: for a particular country, an exogenous $\$ 100$ billion dollar increase in global pharmaceutical expenditures, $\sum_{j \neq k} q_{j, t} p_{j, t}$, is correlated with a 0.081 unit decrease in the country's absolute price index. Since the scale of the price index is somewhat arbitrary, it is useful to note that a 0.081 unit decrease in the price index corresponds to a roughly $7.9 \%{ }^{29}$ decrease. Given the aforementioned endogeneity concerns, if $\alpha<0$ and $\operatorname{Cov}\left(\varepsilon_{k, t}, \sum_{j \neq k}^{*} q_{j, t} p_{j, t}\right)>0 \forall j \neq k^{30}$ we would expect our OLS estimates of $\alpha$ to be biased upwards. When comparing the IV regression (3) to the OLS regression (2) and the IV regression (6) to the OLS regression (5), $\hat{\alpha}$ is indeed higher in the OLS specifications.

The model developed in Section 2 suggests that pharmaceutical prices and domestic pharmaceutical production should be positively related. When controlling for country fixed effects, our estimate of production effects, $\theta$, is positive and significant at the $1 \%$ level in both specifications. The estimate of $\theta$ in column (6) can be roughly interpreted as a $\$ 10$ billion exogenous increase in a country's pharmaceutical production is correlated with a 0.08 unit increase in a country's price index level which corresponds to a 7.8\% decrease in prices. The inclusion of domestic pharmaceutical production is motivated from our theoretical results regarding domestic profit shares and is used as a proxy variable. If domestic production is a poor proxy for domestic profit shares (and potentially countries may not otherwise value domestic production), our estimates could suffer from a measurement error bias. Provided that the measurement error is classical, our estimates of

${ }^{29}$ The percentage change estimate and all preceding percentage change calculations are calculated at the mean price level in the sample, 1.02 .

${ }^{30} \sum_{j \neq k}^{*} q_{j, t} p_{j, t}$ represents the residual from the regression of $\sum_{j \neq k} q_{j, t} p_{j, t}$ on $\delta_{k} x_{k, t}$ and $\widetilde{s}_{k, t}$. 
$\theta$ could suffer from attenuation bias. Consequently, we may be underestimating the domestic supply effect on pharmaceutical prices.

Our theoretical model suggests that the demand, population and GDP per capita are relevant factors in a country's price setting decision. However, our theory only indicates that profits, not necessarily prices will be positively correlated with GDP per capita and population. The empirical estimates suggest both that GDP per capita and population are relevant price setting factors and that the optimal profit level is increasing in GDP per capita and population size. The GDP per capita coefficient estimate is positive and significant in four of the six specifications. Further, the magnitudes of the GDP per capita coefficient estimates seem intuitively plausible. The results from column (1) suggest that a 1,000 increase in GDP per capita is correlated with a roughly 0.01 unit ( $1.0 \%$ change) in pharmaceutical prices.

The relationship between population size and pharmaceutical prices is less clear than the relationship between GDP per capita and prices. The population coefficient is positive in two of the specifications while negative and statistically significant in two of the other specifications. The results from column (5) can be interpreted as a 10 million increase in country's population size is associated with a 0.24 unit (23.5\%) decrease in the price level. Even though the price coefficient is negative, that does not imply that an increase in population size leads to a decrease in profits. For example, suppose a country's population exogenously increases from $\$ 29$ million to $\$ 30$ million people. Our estimates imply the price level will decrease by $2.35 \%$ as a result of the shift in population. Concurrently, the quantity of pharmaceuticals consumed will increase due to the shift in population. Provided that the quantity of pharmaceuticals consumed per capita does not change as a result of the shift in population, profits will increase overall by $1 \%$. 
TABLE 4: ESTIMATION RESULTS

\begin{tabular}{lcccccc}
\hline VARIABLES & $(1)$ & $(2)$ & $(3)$ & $(4)$ & $(5)$ & $(6)$ \\
\hline$\sum_{j \neq i} q_{j, t} p_{j, t},(\hat{\alpha})$ & $-0.81^{* * *}$ & $-0.50^{* * *}$ & $-0.58^{* *}$ & $-0.63^{* *}$ & $-0.83^{* * *}$ & $-0.89^{* * *}$ \\
& $(0.23)$ & $(0.18)$ & $(0.24)$ & $(0.28)$ & $(0.18)$ & $(0.22)$ \\
& & & & -0.02 & $0.06^{* * *}$ & $0.08^{* * *}$ \\
$\tilde{s}_{i, t},(\hat{\theta})$ & & & & $(0.01)$ & $(0.01)$ & $(0.02)$ \\
& & & & $0.02^{* * *}$ & $0.02^{* *}$ & $0.01^{* *}$ \\
GDP Per Capita & $0.01^{* * *}$ & -0.00 & -0.00 & $(0.00)$ & $(0.01)$ & $(0.01)$ \\
& $(0.00)$ & $(0.01)$ & $(0.01)$ & $(0.01)$ & \\
Population & -0.03 & 0.10 & 0.01 & 0.05 & $-2.37^{* * *}$ & $-3.27^{* * *}$ \\
& $(0.02)$ & $(0.25)$ & $(0.30)$ & $(0.07)$ & $(0.63)$ & $(0.74)$ \\
Constant & $1.11^{* * *}$ & $1.26^{* * *}$ & $1.31^{* * *}$ & $0.94^{* * *}$ & $1.17^{* * *}$ & $1.29^{* * *}$ \\
& $(0.11)$ & $(0.08)$ & $(0.10)$ & $(0.12)$ & $(0.12)$ & $(0.15)$ \\
IV & & & $\mathrm{X}$ & & & $\mathrm{X}$ \\
Fixed Effects & & $\mathrm{X}$ & $\mathrm{X}$ & & $\mathrm{X}$ & $\mathrm{X}$ \\
Observations & 210 & 210 & 189 & 144 & 144 & 122 \\
R-squared & 0.369 & 0.913 & 0.918 & 0.534 & 0.949 & 0.949 \\
\hline
\end{tabular}

Notes on Table 4

- One, two and three stars indicate significance at 10, 5 and 1 percent levels.

- The Real Pharmaceutical Price index is scaled across countries using OECD relative prices as discussed in Section 3.2.2.

- In specification (3) and (6) we instrument for $\sum_{j \neq k} q_{j, t} p_{j, t}$ using the weighted (weights lagged by one year) sum of other country covariates (population and GDP per capita). Specification (6) also uses lagged pharmaceutical output as an instrument for pharmaceutical output.

- Population is measured in 100 million people, GDP Per Capita is measured in 10 thousands (2005 USD), and pharmaceutical output is measured in 10 billions (2005 USD)

- The weights $q_{j, t}$ correspond to the quantity of pharmaceuticals consumed in country $\mathrm{j}$ at time $\mathrm{t}$ in terms of trillions dollars (2005 USD). We also construct weights using population and income shares and find quantitatively similar results.

- Specifications (3) and (6) were estimated using two stage least squares. The corresponding Fstatistics for each first stage regression exceed 100. Following Sargan test of over identifying restrictions (1958), we fail to reject the null hypothesis of exogeneity at the $1 \%$ level in specification (3), and fail to reject the null hypothesis of exogeneity at the $10 \%$ level in specification (6).

- As a robustness check we re-estimate the model using alternative pharmaceutical pricing data from Danzon and Furukawa's (2003). Further, we estimate alternative specifications (such as including a time trend) and also re-estimate the model using an unbalanced panel covering 26 OECD countries over the period 1996-2010. Ultimately, we find quantitatively similar results in each robustness check. 
As discussed, the IV estimates displayed in columns (3) and (6) rely on our instruments satisfying the relevance and exogeneity criteria. The F-statistics corresponding to the first stage regressions exceed 100 in each of the three first stage regressions. As there are two endogenous variables in specification (6), examining the F-statistic from the first stage regressions is potentially misleading in terms of assessing the instrument relevancy condition. As a further check, we find that the Shea partial $R^{2}$ exceeds 0.55 for each endogenous variable in specification (6). Since the number of instruments exceeds the number of endogenous variables in both specification (3) and (6) we test the overidentifying restriction. Following the Sargan (1958) test, we fail to reject the null hypothesis of exogeneity at the $10 \%$ level in the full specification in column (6) ${ }^{31}$. Combined with the preceding theoretical justification, we find extensive evidence suggesting that both the exogeneity and relevancy conditions hold.

We run several robustness checks to assess the validity of our estimates in Table 4 . Given the aforementioned concerns regarding the pharmaceutical price data, we reestimate the model after first re-scaling our relative pharmaceutical price index across countries using Danzon and Furukawa's (2003) cross-country relative price index. We find quantitatively similar results in terms of levels and significance, especially with regards to the parameters of interest $\alpha$ and $\theta$. The re-scaled estimates of our preferred specification (Column 6 of Table 4) are statistically indistinguishable from our original estimates. We also find quantitatively similar results when try alternative specifications (such as including time trends, taking logs, etc.) and when using an expanded unbalanced panel data set covering 26 countries over the period 1996-2010.

The empirical findings are in-line with those from the theoretical model. We find that prices are strategic substitutes amongst countries and some limited evidence suggesting that prices are higher in countries with higher demand for pharmaceuticals. It should be noted that it would be a mistake to interpret the estimated coefficients too

\footnotetext{
${ }^{31}$ We also fail to reject the null hypothesis of exogeneity at the $1 \%$ level in specification (3).
} 
literally. The first order condition (3) indicates that the relationship between country k and country j 's prices quite possibly non-linear and heterogeneous; however, we estimate a linear reaction function as simple test for strategic substitutability. Although the exact reaction function remains to be determined, understanding the direction in which country $\mathrm{k}$ responds to price reform in country $\mathrm{j}$ has important policy implications.

\subsection{BRICS and the Future of World Returns}

This section discusses how to use the estimated effects of strategic substitutability in reimbursement, whether in pharmaceuticals as here or in other markets, to estimate the impact of growing world demand on world returns. Using our estimates, we project how the health care and pharmaceutical expenditure growth in BRICS will impact world returns to medical innovation.

Consider the two region case with Country 1 (BRICS) and Country 2 (US). Total Nash equilibrium world returns are

$$
\Pi=\pi_{1}\left(\pi_{2} ; x_{1}, s\right)+\pi_{2}\left(\pi_{1} ; x_{2}, 1-s\right)
$$

Our earlier analysis indicated that future BRICS income growth should lead to an increase in demand for health care and an increase in BRICS returns as well as total world returns.

$$
\frac{\partial \Pi}{\partial x_{1}}=\frac{\partial \pi_{1}}{\partial x_{1}}\left(1+\frac{\partial \pi_{2}}{\partial \pi_{1}}\right)
$$

From our previous analysis we showed that prices are strategic substitutes. Thus, total returns will increase due to the direct demand growth from the BRICS countries but will increase by less than that direct response due to the decrease in profit provision from the US

Suppose the increase in demand from the BRICS countries is associated with a shift in production and profit shares from the US to BRICS such $\Delta s_{1}=-\Delta s_{2}$. The change in profit shares of BRICS results in an increase in profit provision of BRICS but a decrease in US profit provision. 


$$
\frac{\partial \Pi}{\partial s}=\frac{\partial \pi_{1}}{\partial s}-\frac{\partial \pi_{2}}{\partial s} \lesseqgtr 0
$$

The net impact of a shift in profit shares on aggregate profits is thus ambiguous. Putting these two results together the anticipated shift in BRICS demand and profit shares leads to a net increase or decrease in world innovation.

Some simple back of the envelope calculations are useful in illustrating the magnitudes of the tradeoffs involved. In year 2010, total world health care spending was $\$ 4.3$ trillion, of which 7\% percent was from BRICS countries. Now consider a projected two-fold increase in revenues for BRICS countries by 2016 32 . Both our theoretical and empirical analysis indicates that non-BRICS countries will respond to the growth in BRICS by lowering their domestic reimbursements. If non-BRICS countries were to respond to the $100 \%$ increase in BRICS revenues by lowering reimbursements by a mere $7.5 \%$, world revenues would decline overall. The fact that US and other countries currently dominate world returns means that markups reductions need to be fairly small to offset a substantial demand growth in the BRICS.

Our empirical analysis estimated a county's strategic price response to a change in total pharmaceutical revenues as well as its own demand factors. Consider the projected two-fold increase in pharmaceutical revenues stemming from BRICS countries by the year 2016. The projected increase amounts to a roughly $\$ 100$ billion increase in pharmaceutical expenditures from BRICS countries. Our model suggests that a portion and potentially all of the increase in pharmaceutical expenditures could be offset by the strategic pricing responses of richer countries currently dominating the contribution to world returns.

Each country's strategic response to an outside increase world revenues, $\frac{d p_{j}}{d\left(\sum_{j \neq i} q_{j, t} p_{j, t}\right)}$, is given by $\alpha$ in the empirical specification estimated (eq. 5). An exogenous increase in pharmaceutical revenues is equivalent to the term, $\sum_{j \neq i} q_{j, t} p_{j, t}$, increasing by

\footnotetext{
32 This is the suggested growth rate in industry publications, see e.g. IMS Institute's "The Global Use of Medicines Outlook Through 2016"
} 
$\$ 100$ billon in our empirical model. The model estimates indicate that a $\$ 100$ billion increase in pharmaceutical revenues is correlated with a roughly 0.089 unit decrease in a country's price index level, holding all else equal. By aggregating the price response across all countries and holding quantities constant, we are able to estimate the how much of the exogenous increase in pharmaceutical revenues from BRICS countries will potentially be offset by strategic price responses. Letting $\mathcal{B}$ denote the set of BRICS countries, the aggregate impact, in terms of pharmaceutical revenues, of the non-BRICS countries strategic response to the exogenous increase in BRICS revenues is given by:

$$
\Delta \Pi_{\text {Non-BRICS }}=\Delta\left(\sum_{i \notin \mathcal{B}} q_{i} p_{i}\right)=\sum_{i \notin \mathcal{B}}\left(p_{i}+\hat{\alpha} \Delta \sum_{j \in \mathcal{B}} q_{j, t} p_{j, t}\right) q_{i}
$$

where $\Delta\left(\sum_{j \in \mathcal{B}} q_{j, t} p_{j, t}\right)$ represents the exogenous change in global revenues from the BRICS countries which in this case is $\$ 100$ billon. Since quantities are assumed to remain constant, the change in profits corresponds one for one with a change in revenues. Using the estimate $\hat{\alpha}=-0.89$, the above calculation implies that the aggregate strategic response will be roughly $-\$ 37$ billon. In other words, a $\$ 100$ billion exogenous increase in pharmaceutical revenues will be partially offset by a $\$ 37$ billon decrease in pharmaceutical revenues as countries strategically respond by lowering their pharmaceutical prices.

The $\$ 37$ billion strategic response should be thought of as an upper bound (in terms of the magnitude of the response) for several reasons. First, by fixing quantities we are overstating the impact decreasing pharmaceutical prices will have on pharmaceutical revenues. As prices fall, the decline in revenues will be less in percentage terms than a one for one. The quantity of pharmaceuticals demanded will increase as prices fall which offset some of the corresponding decline in revenues. Secondly, the above analysis ignores secondary price responses. For example, if the US knows that the strategic response of other countries will partially offset the exogenous increase world pharmaceutical revenues, the US will lower its prices by a smaller amount than it would have otherwise. Regardless of the exact magnitude, our model indicates that a sizeable amount of the pharmaceutical 
expenditure growth stemming from the BRICS countries will be offset by the strategic responses of other countries.

As discussed previously, the increase in BRICS may also be associated with a shift concentration in the ownership of profits which in addition to demand growth affects reimbursement policies. Consider when $10 \%$ of US profits (as represented by production in our empirical analysis) shifts to the BRICS countries over the next few years. The theoretical and empirical results predict that this shift will result in a decrease in US prices and an increase in BRICS prices. Figures 6 and 7 illustrate the estimated impact BRICS growth will have on future pharmaceutical and total health care revenues when production shifts from the US to the BRICS countries. Using data from the pharmaceutical sector, in section 3.2 we estimate that for every $\$ 1$ increase in BRICS pharmaceutical spending leads to only an increase of $\$ 0.63$ in in total pharmaceutical revenues. In Figures 6 and 7 we analyze the implications of this offset assuming it extended to overall health care reimbursements as well as for pharmaceuticals alone. The separate impact of the production shift on world returns is calculated with the estimate $\hat{\theta}=0.008$ from the preceding analysis of pharmaceutical pricing. As BRICS countries represent $15 \%$ of the pharmaceutical market and only $7 \%$ of the total health care market, an increase the BRICS growth (in percentage terms) has a much larger impact on the pharmaceutical market than the total health care market. Given the $10 \%$ shift in production, BRICS health care (pharmaceutical) revenue growth would have to increase by over $270 \%$ (126\%) for world revenues to increase overall. The main point these quantitative effects imply is that when both demand and supply growth occurs through the BRICS, reasonable parameter levels suggests that a fall (as opposed to a rise) in world returns may result. 


\section{Figure 6: Future World Returns (Total Health CARE)}

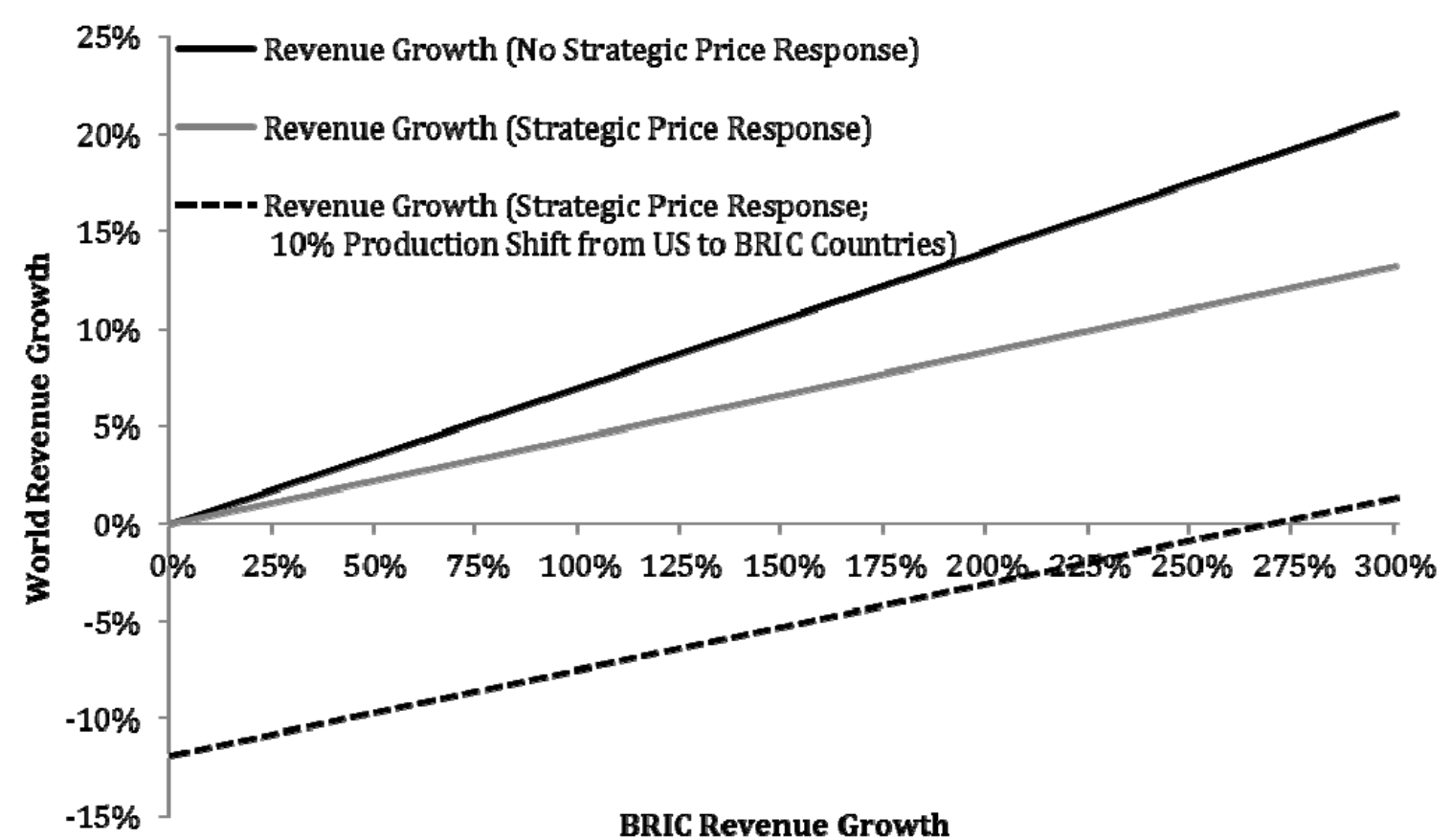

Figure 7: Future World Returns (Pharmaceuticals)

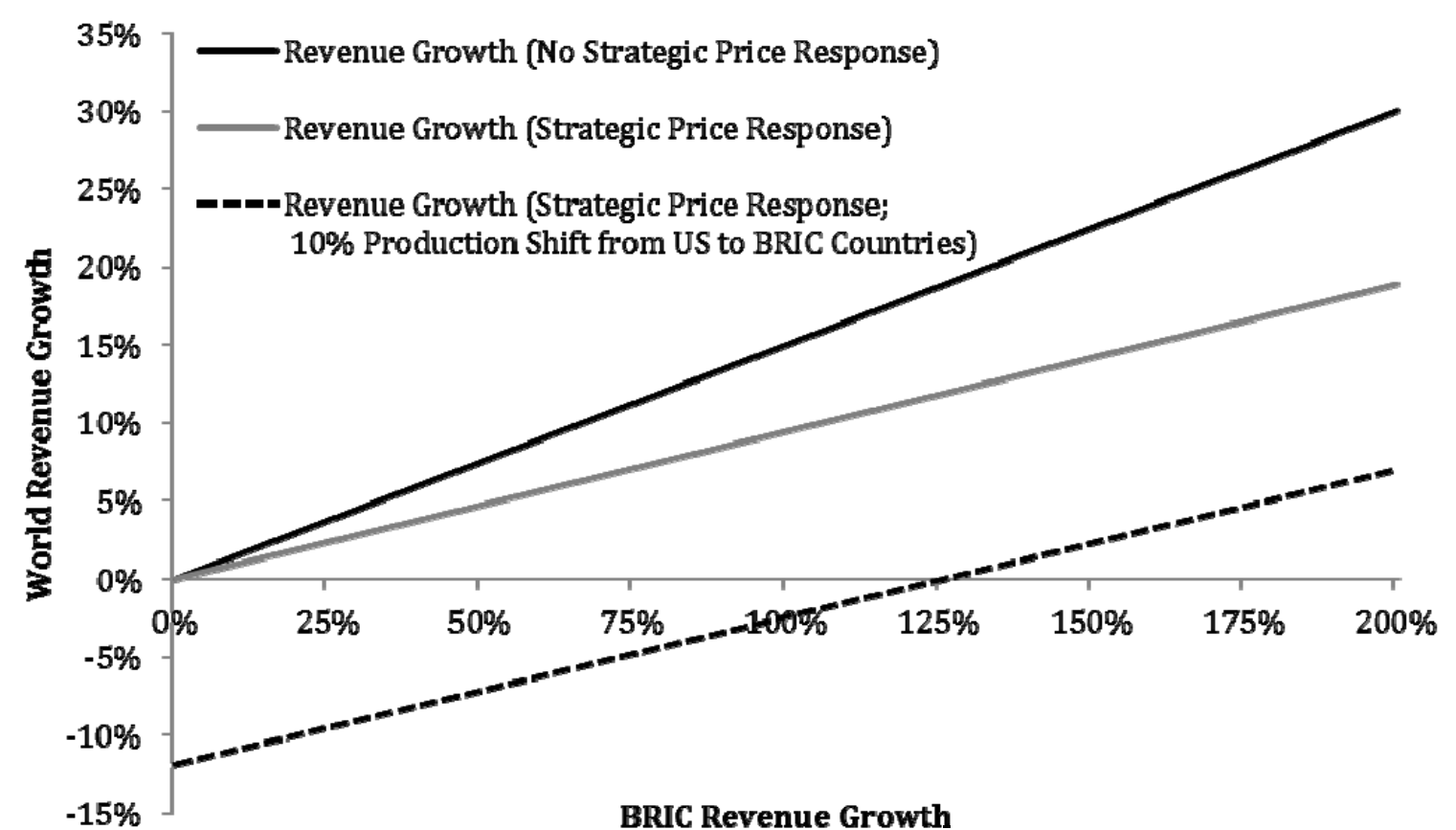


These quantitative effects suggest that demand growth in BRICS countries has the potential to expand pharmaceutical returns and consequently stimulate further medical innovations. However, the strategic responses of existing developed countries could largely offset and even decrease world returns to innovation and the larger spending growth it may entail. This is especially true if the expected increase in demand is accompanied by a shift in ownership to the BRICS.

\section{Conclusions and Further Research}

Because world returns drive innovation and because innovation is central to health care spending growth, health care economies and policies of other countries thereby drastically affect domestic spending growth. This paper analyzed the unique positive and normative implications of these innovation-induced linkages across countries when governments centrally price health care. We stressed the implications of the inherent public-goods problem in providing world returns when taxation to fund reimbursements involves a domestic cost with an international benefit. Because of this public-goods problem, medical innovations have inefficiently low world returns, and reimbursements were predicted to be "strategic substitutes." We argued that the public-goods aspect of medical innovation creates a significant concern in the concentration of world demand and supply. We provided an empirical analysis of the effects of the future decline in this concentration on world returns by considering the plausible conditions under which future growth of the BRICS may lower world returns.

We conclude by discussing some of the implications of our analysis as well as future areas of research.

\subsection{Domestic and Regional Health Care Reforms}

Our analysis implies that health care reforms that aim to curb spending growth will have different effects, depending on a country's importance for world returns. Put differently, reforms in small countries will not affect spending growth rates induced by 
innovation, although US reforms will. For the same reason, using US states as "laboratories for reform" does not capture innovation or growth effects because individual states do not affect world returns. For example, even though reforms in Massachusetts were similar to the federal Affordable Care Act (ACA) reforms, the lessons learned about the impact on growth of spending are minimal if that state does not affect world returns. Likewise, the many regional payment demonstration experiments that ACA is financing do not address spending growth induced by world returns to innovation. Rather, differences in technology adoption procedures appear to be a key factor affecting regional spending growth in the face of world returns driving common innovations across countries. Indeed, our analysis implies that subnational or regional reimbursement levels will be lower than national ones. For example, state Medicaid programs are predicted, as observed, to price below the federal Medicare program in the United States, even though Medicare clearly is a bigger buyer with larger bargaining power. Future research should investigate the impact of regional versus national public reimbursement policies.

\subsection{International Spending Levels and Growth Rates}

Our analysis can be developed further to examine international spending patterns across countries, particularly as those spending patterns are often attributable to differences in pricing rather than use. If innovation is a public good that drives spending growth and is used by everyone, it suggests less variance in growth rates across countries than that in levels due to the differential markup incentives discussed. More generally, a better understanding of the incentives that determine the growth in reimbursements over time implied by our analysis, rather than the levels analyzed here, seems a useful avenue of research.

\subsection{An Evaluation of Domestic Underpricing through Existing Pricing Regimes}

Since efficient world pricing can be viewed as a classic public-goods problem, standard remedies to avoid free riding in providing public goods seem relevant. As is common under positive external effects, the behavior of interest is underprovided, and efficiency gains can be achieved with Pigouvian subsidies that aim to equate the domestic 
costs of markup provision providing the world's benefit in terms of generating new innovations. Evaluating the efficiency effects of international reimbursement reforms in this context seems to be worthwhile. In particular, more centralized European Union (EU) pricing may raise innovative returns rather than the separate domestic pricing by individual countries. This would be the reimbursement analog to the more advanced European Medicines Agency (EMA) harmonization for approval processes in the EU. If countries unified their reimbursement decisions, it might raise prices to more efficient levels. The obvious counterargument is that a larger buyer forces down prices more, but as we have shown, that is not always the case. Smaller countries are free riding more, in an individually optimal manner, by keeping reimbursements low.

\subsection{Personalized Medicine}

Many analysts have argued that personalized medicines and orphan drugs are likely to reduce market size for therapies. Clearly, the growth of world markets, in particular, the BRICS, may well substantially increase the use of domestic orphan drugs in a world market, thus aggregating the orphan status within each country across new, large economies such as the BRICS. However, the free-riding incentives discussed here mitigate the positive impact on world returns. A valuable course of research may lie in investigating the degree to which emerging markets affect the incentives for innovation of rare diseases or personalized medicines, often argued to be plagued by low innovation incentives due to small market size.

Overall, more quantitative analysis is needed concerning the impact of innovationinduced linkages across health care economies, both for positive analysis to explain differences in reimbursements and spending and for normative analysis of what policies function in a given country's self-interest. 


\section{References}

Becker, G. S., Philipson, T. J., \& Soares, R. R. (2005). The Quantity and Quality of Life and the Evolution of World Inequality. The American Economic Review, 95(1), 277-291.

Besley, T., \& Case, A. (1995). Incumbent behavior: Vote-Seeking, Tax-Setting, and Yardstick Competition. American Economic Review, 85(1), 25-45.

Brueckner, J. K. (2003). Strategic Interaction Among Governments: An Overview of Empirical Studies. International Regional Science Review, 26(2), 175-188.

Danzon, P. M., \& Furukawa, M. F. (2003). Prices and Availability of Pharmaceuticals: Evidence from Nine Countries. Health Affairs., Web Exclusive W3, 521-536

Danzon, P. M. (1997). Price Discrimination for Pharmaceuticals: Welfare Effects in the US and the EU. International Journal of the Economics of Business, 4(3), 301-322.

Danzon, P. M., \& Towse, A. (2003). Differential Pricing for Pharmaceuticals: Reconciling Access, R\&D and Patents. International Journal of Health Care Finance and Economics, 3(3), 183-205.

Figlio, D. N., Kolpin, V. W., \& Reid, W. E. (1999). Do States Play Welfare Games?. Journal of Urban economics, 46(3), 437-454.

Fredriksson, P. G., \& Millimet, D. L. (2002). Strategic Interaction and the Determination of Environmental Policy Across US states. Journal of Urban Economics, 51(1), 101-122.

Gerdtham, U. G., \& Jönsson, B. (2000). International Comparisons of Health Expenditure: Theory, Data and Econometric Analysis. Handbook of Health Economics, 1, 11-53.

Golec, J. H., \& Vernon, J. A. (2006). European Pharmaceutical Price Regulation, Firm Profitability, and R\&D Spending. National Bureau of Economic Research, No. w12676.

Hult, K. J., \& Philipson, T. J. (2012). Health Care Reforms and the Value of Future Public Liabilities. National Bureau of Economic Research, No. w18571. 
Jena, A. B., \& Philipson, T. J. (2008). Cost-effectiveness Analysis and Innovation. Journal of Health Economics, 27(5), 1224-1236.

Lakdawalla, D. N et al. (2009). US Pharmaceutical Policy in a Global Marketplace. Health Affairs, 28(1), w138-w150.

Newhouse, J. P. (1992). Medical Care Costs: How Much Welfare Loss? The Journal of Economic Perspectives, 6(3), 3-21.

OECD Health Policy Studies (2008). Pharmaceutical Pricing Policies in a Global Market. OECD.

Shea, J. (1997). Instrument Relevance in Multivariate Linear Models: A Simple Measure. Review of Economics and Statistics, 79(2), 348-352.

Sargan, J. D. (1958). The Estimation of Economic Relationships Using Instrumental Variables. Econometrica: Journal of the Econometric Society, 393-415.

Villas-Boas, J. M., \& Winer, R. S. (1999). Endogeneity in Brand Choice Models. Management Science, 45(10), 1324-1338.

World Health Organization. (2004). The World Medicines Situation. Geneva: World Health Organization. 


\section{Appendix: Impact of a Change in Ownership on Total Profits}

Consider the two country example with countries 1 and 2 where the ownership share of Country 1 increases by $d s_{1}$ and the ownership share of Country 2 correspondingly decreases by $d s_{2}=-d s_{1}$. We rewrite first order condition (3) as follows (where the demand arguments of consumer surplus are omitted for convenience):

$$
0=\left[c_{1}^{\prime}\left(\pi_{1}\right)+s_{1}\right] P(\Pi)+\left[c_{1}\left(\pi_{1}\right)+s_{1} \Pi\right] P^{\prime}(\Pi)
$$

Totally differentiating the above equation yields

$$
\begin{aligned}
0= & {\left[P(\Pi)+\Pi P^{\prime}(\Pi)\right] d s_{1} } \\
& +\left[c_{1}^{\prime \prime}\left(\pi_{1}\right) P(\Pi)+2\left(c_{1}^{\prime}\left(\pi_{1}\right)+s_{1}\right) P^{\prime}(\Pi)+\left(c_{1}\left(\pi_{1}\right)+s_{1} \Pi\right) P^{\prime \prime}(\Pi)\right] d \pi_{1} \\
& +\left[\left(c_{1}^{\prime}\left(\pi_{1}\right)+s_{1}\right) P^{\prime}(\Pi)+\left(c_{1}\left(\pi_{1}\right)+s_{1} \Pi\right) P^{\prime \prime}(\Pi)+s_{1} P^{\prime}(\Pi)\right] d \pi_{2}
\end{aligned}
$$

For convenience we define the terms $A_{1}$ and $B_{1}$ such that the above total differential can be rewritten as

$$
0=\left[P(\Pi)+\Pi P^{\prime}(\Pi) d s_{1}+A_{1} d \pi_{1}+B_{1} d \pi_{2}\right.
$$

Rearranging the above equation, we have that

$$
\frac{d \pi_{1}}{d s_{1}}=\frac{-\left[P(\Pi)+\Pi P^{\prime}(\Pi)\right]}{A_{1}}-\frac{B_{1}}{A_{1}} \frac{d \pi_{2}}{d s_{1}}
$$

By symmetry, and noting that $d s_{2}=-d s_{1}$, we can substitute in for $\frac{d \pi_{2}}{d s_{1}}$ in the above equation and solve for $\frac{d \pi_{1}}{d s_{1}}$.

$$
\frac{d \pi_{1}}{d s_{1}}=\left[P(\Pi)+\Pi P^{\prime}(\Pi)\right]\left(\frac{B_{1}-A_{2}}{A_{1} A_{2}+B_{1} B_{2}}\right)
$$

Where $A_{2}$ and $B_{2}$ correspond to the terms $A_{1}$ and $A_{2}$ defined for Country 2 rather than Country 1.

The change in total equilibrium profits, resulting from a change in profits is equal to 


$$
\begin{aligned}
\frac{d \Pi}{d s_{1}} & =\frac{d \pi_{1}}{d s_{1}}+\frac{d \pi_{2}}{d s_{1}} \\
& =\left[P(\Pi)+\Pi P^{\prime}(\Pi)\right] \frac{A_{1}+B_{1}-A_{2}-B_{2}}{A_{1} A_{2}+B_{1} B_{2}}
\end{aligned}
$$

The sign thus depends on the levels and curvatures of the social cost and probability of innovation functions. In the simple parametric example discussed in Section 2, it is straightforward to generate cases in which a change in profit shares increases total profits, decreases total profits, and does not change total profits. 